\title{
Updating the Finite Element Model of the Aerostructures Test Wing Using Ground Vibration Test Data
}

\author{
Shun-fat Lung ${ }^{*}$ and Chan-gi Pak ${ }^{\dagger}$ \\ NASA Dryden Flight Research Center, Edwards, CA 93523-0273
}

\begin{abstract}
Improved and/or accelerated decision making is a crucial step during flutter certification processes. Unfortunately, most finite element structural dynamics models have uncertainties associated with model validity. Tuning the finite element model using measured data to minimize the model uncertainties is a challenging task in the area of structural dynamics. The model tuning process requires not only satisfactory correlations between analytical and experimental results, but also the retention of the mass and stiffness properties of the structures. Minimizing the difference between analytical and experimental results is a type of optimization problem. By utilizing the multidisciplinary design, analysis, and optimization (MDAO) tool in order to optimize the objective function and constraints; the mass properties, the natural frequencies, and the mode shapes can be matched to the target data to retain the mass matrix orthogonality. This approach has been applied to minimize the model uncertainties for the structural dynamics model of the Aerostructures Test Wing (ATW), which was designed and tested at the National Aeronautics and Space Administration (NASA) Dryden Flight Research Center (DFRC) (Edwards, California). This study has shown that natural frequencies and corresponding mode shapes from the updated finite element model have excellent agreement with corresponding measured data.
\end{abstract}

\section{Nomenclature}

$\begin{array}{ll}\text { AR } & =\text { aspect ratio } \\ \text { ATW } & =\text { aerostructures test wing } \\ \text { CG } & =\text { center of gravity } \\ \text { DFRC } & =\text { Dryden Flight Research Center } \\ \text { DOF } & =\text { degrees of freedom } \\ \text { DPR } & =\text { driving point residues } \\ \text { d } & =\text { number of degrees of freedom } \\ \text { E } & =\text { effective independent matrix } \\ \text { EI } & =\text { effective independence } \\ \text { F } & =\text { original objective function } \\ \text { FE } & =\text { finite element } \\ \text { FIM } & =\text { Fisher information matrix } \\ \text { G } & =\text { subscript for target values (or measured quantities) } \\ \text { GA } & =\text { genetic algorithm } \\ \text { GVT } & =\text { ground vibration test } \\ \mathrm{g}_{\mathrm{i}} & =\text { inequality constraints } \\ \mathrm{h}_{\mathrm{j}} & =\text { equality constraints } \\ \mathrm{I}_{\mathrm{XX}} & =\text { computed } x \text { moment of inertia about the center of gravity } \\ \mathrm{I}_{\mathrm{XXG}} & =\text { target } x \text { moment of inertia about the center of gravity } \\ \mathrm{I}_{\mathrm{Xy}} & =\text { computed xy moment of inertia about the center of gravity } \\ \mathrm{I}_{\mathrm{XYG}} & =\text { target xy moment of inertia about the center of gravity } \\ \mathrm{I}_{\mathrm{YY}} & =\text { computed y moment of inertia about the center of gravity } \\ \mathrm{I}_{\mathrm{YYG}} & =\text { target y moment of inertia about the center of gravity } \\ \mathrm{I}_{\mathrm{YZ}} & =\text { computed yz moment of inertia about the center of gravity } \\ & \end{array}$

\footnotetext{
${ }^{*}$ Research Engineer, Aerostructures Branch, P.O. Box 273/48202A, AIAA Member.

${ }^{\dagger}$ Group Lead, Structural Dynamics Group, P.O. Box 273/48202A, AIAA Member.
} 


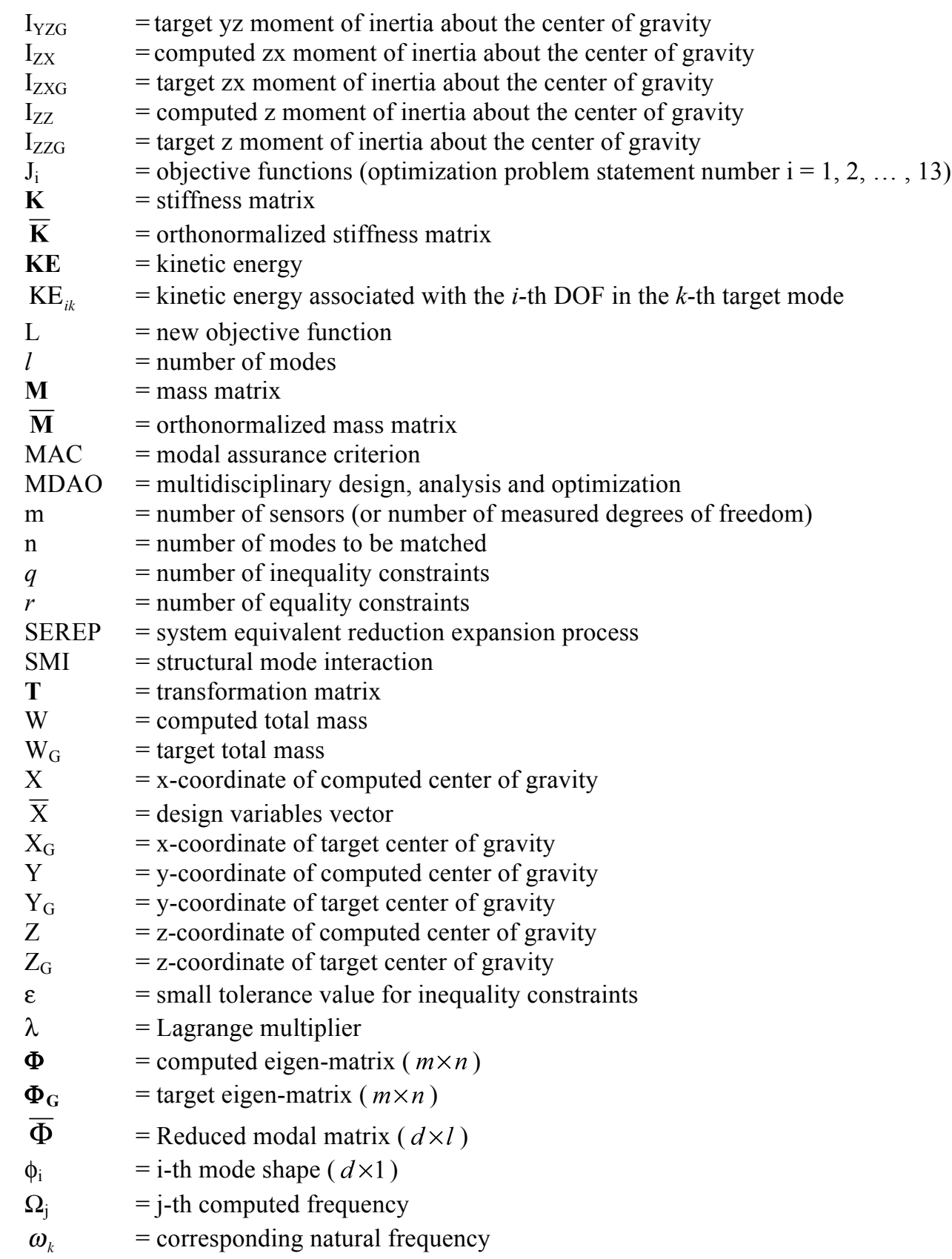

\title{
I. Introduction
}

\begin{abstract}
test article called the aerostructures test wing (ATW) was developed and flown at the National Aeronautics and Space Administration (NASA) Dryden Flight Research Center (DFRC) (Edwards, California) on the McDonnell Douglas NF15B test bed aircraft as shown in Fig. 1 for the purpose of demonstrating and validating flutter prediction methods during flight. ${ }^{1}$ The first aerostructures test wing (ATW1), flown in 2001, was originally developed to directly address requests for better flight flutter test techniques by providing a functional flight test platform. While the first series of tests was extremely successful, the minimum amount of instrumentation (structural accelerometers and strain gages) was chosen to satisfy the scope of the program. These sensors were limited in their capability to answer questions of aeroelastic interactions, sources of nonlinearity, physical mechanisms of aeroelastic coupling, and feedback dynamics between the structure and aerodynamics.
\end{abstract}




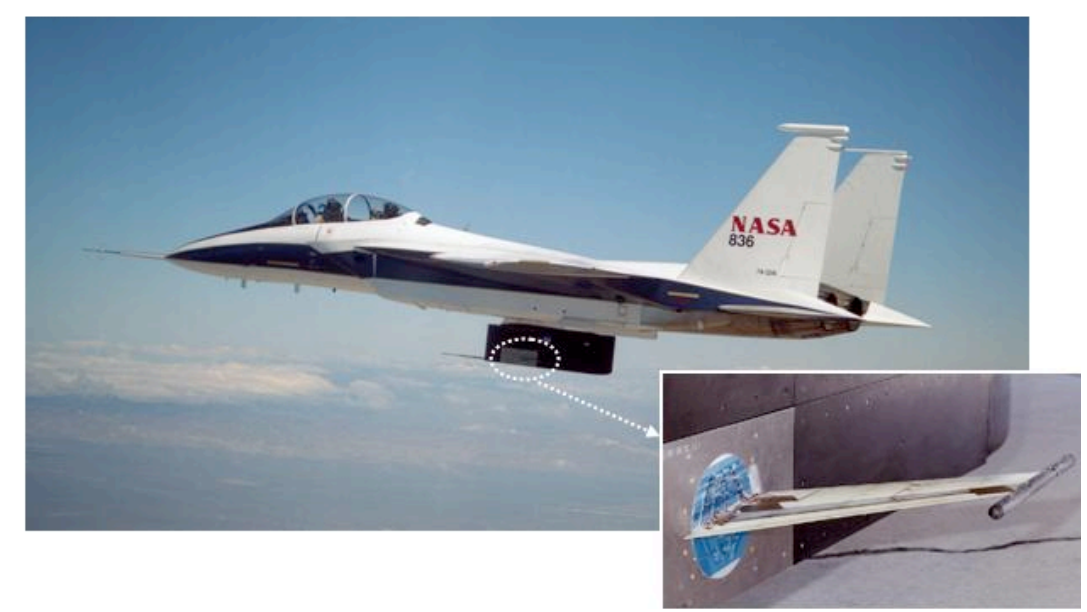

Figure 1. Aerostructures test wing mounted on the NF15B for flight flutter testing.

A second aerostructures test wing (ATW2), as shown in Fig. 2, was built for the demonstration of state-of-the-art sensor technologies for simultaneous; distributed; collocated measurement of shear stress (skin friction); steady and unsteady pressures; and structural strain and accelerations for mode shapes as well as other modal properties. Like the ATW1, the ATW2 was flown on the NF15B aircraft. In order to have a successful prediction of the onset flutter, the structural dynamics finite element (FE) model has to be robust and accurate. The ground vibration test (GVT) is used as one of the validation methods for robustness of the FE model.

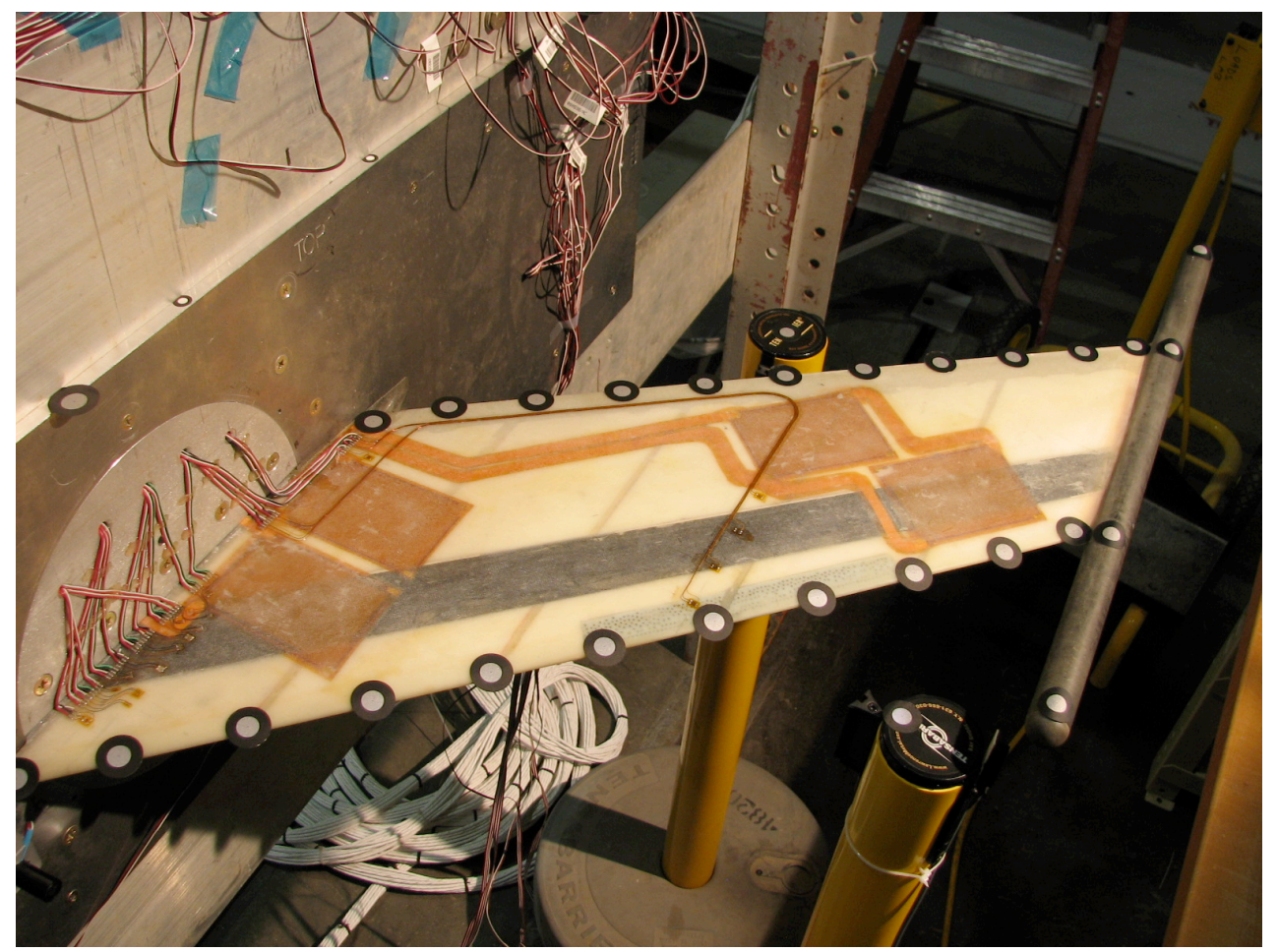

Figure 2. Aerostructures test wing 2.

The primary objective of this study is to obtain the GVT validated structural dynamics FE model for minimizing model uncertainties in the predicted flutter boundaries. Discrepancies are common between the test data and the analytical results. However, the FE model can be fine tuned through the use of the GVT data. Accurate and reliable GVT results are important to this adjusting process. Selection of measurement locations can be critical to the success 
of an experimental modal survey. So, different sensor and exciter placement algorithms for pre-test evaluations were investigated to ensure the quality of the modal test.

Manual trial-and-error methods provide an inefficient approach to correlate the FE model with test data. A more efficient approach is to use a mode matching technique for the model refinement of both ground and flight-based models. A model tuning technique utilized was NASA Dryden's multidisciplinary design, analysis, and optimization (MDAO) tool, ${ }^{2}$ which was used to adjust the structural properties so that the analytical results and the measured data were matched.

\section{Sensor/Actuator Placement Methods}

It is important to assure that an adequate number of proper sensor locations are identified for the collection of data during the GVT. There are several existing techniques that can be used for the determination of measurement locations. These algorithms start with a full or selected set of finite element degrees of freedom (DOFs) with the desired number of mode shapes as shown in Eq. (1):

$$
\bar{\Phi}=\left[\phi_{1} \phi_{2} \ldots \phi_{l}\right]
$$

where $\bar{\Phi}$ is the reduced modal matrix $(d \times l)$. Depending on the algorithm, the unwanted DOFs can be eliminated in one cycle or iteratively until the desired number of sensors is reached.

\section{A. Effective Independence:}

The objective of the effective independence (EI) method is to select sensor locations that make the target modes linearly independent, while retaining as much information as possible. This procedure starts from a large set of candidate sensor locations in which the effective independence matrix $\boldsymbol{E}$ can be formed as shown in Eq. (2). ${ }^{3}$

$$
\boldsymbol{E}=\bar{\Phi}\left(\Phi^{T} \bar{\Phi}\right)^{-1} \bar{\Phi}^{T}
$$

The DOF with the smallest value is removed and the $\boldsymbol{E}$ matrix is re-calculated for the new candidate set. The iterative process continues until the desired number of sensors is reached.

\section{B. Genetic Algorithm:}

Selection of the sensor locations is a kind of optimization problem with discrete design variables. One of the solution methods for this optimization problem is the genetic algorithm (GA) ${ }^{4}$ Using the determinant of the Fisher information matrix (FIM) as objective function, and sensor locations as design variables, the optimal sensor locations can be determined. The FIM is defined as shown in Eq. (3). ${ }^{5}$

$$
\mathbf{F I M} \equiv \bar{\Phi}^{T} \bar{\Phi}
$$

The sensor locations, which are based on the desired number of sensors, are randomly picked and the GA method will find the best set of locations that gives the maximum determinant value of the FIM. The determinant of the FIM indicates the amount of information in the data that is retained at the reduced set of coordinates. Maintaining a high value for this determinant is desired so that the FIM retains as much information as possible. The optimization problem statement can be written as:

Maximize the objective function $o b j=\operatorname{det}(\mathbf{F I M})$ for any set of sensor positions with no constraint equations.

\section{Kinetic Energy Sorting:}

The kinetic energy sorting technique involves an examination of each DOF's contribution of kinetic energy to each mode shape. The calculation of the kinetic energy in terms of the mode shapes can be expressed as shown in Eq. (4):

$$
\mathrm{KE}_{i k}=\bar{\Phi}_{i k} \sum_{j} \mathrm{M}_{i j} \bar{\Phi}_{j k}
$$


where $\mathrm{KE}_{i k}$ is the kinetic energy associated with the $i$-th DOF in the $k$-th target mode. The total kinetic energy for each DOF is the summation of the normalized kinetic energy of each DOF for each mode. Those DOFs having the greatest contribution or most kinetic energy can be identified and selected as sensor locations.

\section{Guyan Reduction:}

The purpose of the Guyan reduction ${ }^{6}$ is to remove the number of DOFs in a large FE model, but still maintain the characteristics of the original model at the lower frequencies. Higher frequency modes are neglected because these DOFs can be removed based on the fact that the inertia forces are negligible compared with the elastic forces. This process involves examining the ratio of stiffness over mass for each DOF. If the ratio is small, then there are significant inertia effects associated with the DOF, and thus it should be retained. If the ratio is large, then the inertia effects are negligible and the corresponding DOF can be removed.

\section{E. Iterative Guyan Reduction:}

Unlike the standard Guyan reduction, the iterative Guyan reduction ${ }^{7}$ removes the DOF one at a time so that at each stage the effect of each DOF removed is redistributed to all of the remaining DOFs, resulting in greater accuracy than the non-iterative approach.

\section{F. Driving Point Residues:}

Driving point residues (DPR) are equivalent to modal participation factors. They are proportional to the magnitude of the mode shapes. A driving point is a point in the structure where the excitation DOF and the response are equal. If the modal matrix is mass normalized, then the driving point residues for the DOF $i$ of the mode shape $k$ can be computed ${ }^{8}$ as shown in Eq. (5):

$$
D P R_{k}(i, i)=\frac{\bar{\Phi}(i) \otimes \bar{\Phi}(i)}{\omega_{k}}
$$

where $\omega_{k}$ is the corresponding natural frequency and $\otimes$ is the element-by-element multiplication operator. The normalized DPR can then be used to calculate the average, minimum, maximum, and weighted modal displacement of all the target modes. The optimal sensor/exciter locations are then selected based on the values of the weighted driving point residue and the number of sensors/actuators available for the test. In this study, the weighted minimum was used for the selection of the sensor locations in order to opt out of those DOFs at the nodal point of a mode. The weighted minimum DPR was obtained as shown in Eq. (6).

$$
D P R_{\text {weighted }}(i)=\min _{j=1}^{n} \overline{D P R}_{j}(i, i) \cdot \frac{1}{n} \sum_{j=1}^{n} \overline{D P R}_{j}(i, i)
$$

The weighted maximum was used for the selection of the excitation locations so that those easily excited DOFs could be identified. The weighted maximum DPR can be expressed as shown in Eq. (7):

$$
D P R_{\text {weighted }}(i)=\max _{j=1}^{n} \overline{D P R}_{j}(i, i) \cdot \frac{1}{n} \sum_{j=1}^{n} \overline{D P R}_{j}(i, i)
$$

where $\overline{D P R}$ is the normalized DPR.

\section{Structural Dynamic Model Tuning Procedure}

Discrepancies in frequencies and mode shapes are minimized using a series of optimization procedures. ${ }^{9-11}$ There are two optimization algorithms adopted in NASA Dryden's MDAO tool: the traditional gradient-based algorithm ${ }^{12}$ and the genetic algorithm. Gradient-based algorithms work well for continuous design variable problems, whereas GAs can handle continuous as well as discrete design variable problems easily. When there are multiple local minima, GAs are able to find the global optimum results, whereas gradient-based methods may converge to a locally minimum value. In this research work, the GA was used for the solution of the optimization problem. 
The GA is directly applicable only to unconstrained optimization; it is necessary to use some additional methods in order to solve the constrained optimization problem. The most popular approach is to add penalty functions in proportion to the magnitude of constraint violation to the objective function. ${ }^{13}$ The general form of the penalty function is shown in Eq. (8):

$$
\mathrm{L}(\overline{\mathrm{X}})=\mathrm{F}(\overline{\mathrm{X}})+\sum_{i=1}^{q} \lambda_{i} \mathrm{~g}_{i}(\overline{\mathrm{X}})+\sum_{j=1}^{r} \lambda_{j+q} \mathrm{~h}_{j}(\overline{\mathrm{X}})
$$

where $\mathrm{L}(\overline{\mathrm{X}})$ indicates the new objective function to be optimized, $\mathrm{F}(\overline{\mathrm{X}})$ is the original objective function, $\mathrm{g}_{i}(\overline{\mathrm{X}})$ is the inequality constraint, $\mathrm{h}_{j}(\overline{\mathrm{X}})$ is the equality constraint, $\lambda_{i}$ are the Lagrange multipliers, $\overline{\mathrm{X}}$ is the design variables vector, and $q$ and $r$ are the number of inequality and equality constraints, respectively.

The analytical mass properties, the mass matrix orthogonality, and the natural frequencies and mode shapes are matched to the target values based on the following three tuning steps.

\section{A. Step 1: Tuning mass properties}

The difference in the analytical and target values of the total mass, the center of gravity (CG) location, and the mass moment of inertias at the CG location are minimized to have the improved rigid body dynamics as shown in Eqs. (9) through (18).

$$
\begin{aligned}
\mathrm{J}_{1} & =\left(\mathrm{W}-\mathrm{W}_{G}\right)^{2} / \mathrm{W}_{G}^{2} \\
\mathrm{~J}_{2} & =\left(\mathrm{X}-\mathrm{X}_{G}\right)^{2} / \mathrm{X}_{G}^{2} \\
\mathrm{~J}_{3} & =\left(\mathrm{Y}-\mathrm{Y}_{G}\right)^{2} / \mathrm{Y}_{G}^{2} \\
\mathrm{~J}_{4} & =\left(\mathrm{Z}-\mathrm{Z}_{G}\right)^{2} / \mathrm{Z}_{G}^{2} \\
\mathrm{~J}_{5} & =\left(\mathrm{I}_{\mathrm{XX}}-\mathrm{I}_{\mathrm{XX}_{G}}\right)^{2} / \mathrm{I}_{\mathrm{XXG}}^{2} \\
\mathrm{~J}_{6} & =\left(\mathrm{I}_{\mathrm{YY}}-\mathrm{I}_{\mathrm{YY}_{G}}\right)^{2} / \mathrm{I}_{\mathrm{YY} G}^{2} \\
\mathrm{~J}_{7} & =\left(\mathrm{I}_{\mathrm{ZZ}}-\mathrm{I}_{\mathrm{ZZ} G}\right)^{2} / \mathrm{I}_{\mathrm{ZZG}}^{2} \\
\mathrm{~J}_{8} & =\left(\mathrm{I}_{\mathrm{XY}}-\mathrm{I}_{\mathrm{XY}}\right)^{2} / \mathrm{I}_{\mathrm{XYG}}^{2} \\
\mathrm{~J}_{9} & =\left(\mathrm{I}_{\mathrm{YZ}}-\mathrm{I}_{\mathrm{YZG}_{G}}\right)^{2} / \mathrm{I}_{\mathrm{YZG}}^{2} \\
\mathrm{~J}_{10} & =\left(\mathrm{I}_{\mathrm{ZX}}-\mathrm{I}_{\mathrm{ZX} G}\right)^{2} / \mathrm{I}_{\mathrm{ZX} G}^{2}
\end{aligned}
$$

\section{B. Step 2: Tuning mass matrix}

The off-diagonal terms of the orthonormalized mass matrix are reduced to improve the mass orthogonality as shown in Eq. (19):

$$
\mathrm{J}_{11}=\sum_{i=1, j=1, i \neq j}^{n}\left(\overline{\mathbf{M}}_{i j}\right)^{2}
$$

where $n$ is the number of modes to be matched and $\overline{\mathbf{M}}$ is defined as shown in Eq. (20).

$$
\overline{\mathbf{M}}=\Phi_{G}^{T} \mathbf{T}^{T} \mathbf{M T} \Phi_{G}
$$

In the above equation, the mass matrix $\mathbf{M}$ is calculated from the FE model, while the target eigen-matrix $\Phi_{G}$ is measured from the GVT. The eigen-matrix $\Phi_{G}$ remains constant during the optimization procedure. A transformation matrix $\mathbf{T}$ in the above equation is based on Guyan reduction, improved reduction system ${ }^{14}$ or the system equivalent reduction expansion process (SEREP). ${ }^{15}$ This reduction is required due to the limited number of available sensor locations and difficulties in measuring the rotational DOFs. 


\section{Step 3: Tuning frequencies and mode shapes}

Two different types of approach can be used for tuning the frequencies and mode shapes. In the first option, shown in Eqs. (21) and (22), the objective function considered combines the normalized errors between GVT and computed frequencies with the total error associated with the off-diagonal terms of the orthonormalized stiffness matrix.

$$
\begin{gathered}
\mathrm{J}_{12}=\sum_{i=1}^{n}\left(\frac{\Omega_{i}-\Omega_{i G}}{\Omega_{i}}\right)^{2} \\
\mathrm{~J}_{13}=\sum_{i=1, j=1, i \neq j}^{n}\left(\overline{\mathbf{K}}_{i j}\right)^{2}
\end{gathered}
$$

The matrix $\overline{\mathbf{K}}$ are obtained from the matrix products as shown in Eq. (23):

$$
\overline{\mathbf{K}}=\Phi_{\mathrm{G}}^{T} \mathbf{T}^{T} \mathbf{K} \mathbf{T} \Phi_{\mathrm{G}}
$$

where the stiffness matrix, $\mathbf{K}$, is calculated from the FE model.

In the second option, shown in Eqs. (24) and (25), the error norm combines the normalized error between GVT and computed frequencies with the total error between the GVT and computed mode shapes at given sensor points.

$$
\begin{gathered}
\mathrm{J}_{12}=\sum_{i=1}^{n}\left(\frac{\Omega_{i}-\Omega_{i G}}{\Omega_{i}}\right)^{2} \\
\mathrm{~J}_{13}=\sum_{i=1}^{m} \sum_{j=1}^{n}\left(\Phi_{i j}-\Phi_{i j G}\right)^{2}
\end{gathered}
$$

In this study, the second option for tuning frequencies and mode shapes was employed since the definition of the objective function is much simpler than in the first option for this application. Any errors in both the modal frequencies and the mode shapes are minimized by including an index for each of these in the objective function. For this option, a small number of sensor locations can be used at which errors between the GVT and computed mode shapes are obtained. Any one of $\mathrm{J}_{1}$ thru $\mathrm{J}_{13}$ can be used as the objective function with the others treated as constraints. This gives the flexibility to achieve the particular optimization goal while maintaining the other properties at as close to the desired target value as possible. The optimization problem statement can be written as

Minimize $\mathrm{J}_{i}$

Such that $\mathrm{J}_{k} \leq \varepsilon_{k}$, for $k=1$ thru 13 and $k \neq i$

where $\varepsilon_{\mathrm{k}}$ is a small value which can be adjusted according to the tolerance of each constraint condition.

\section{Test Article}

The ATW2 was used to demonstrate NASA Dryden's MDAO tool through the process of ground vibration testing and the model tuning technique. This test article was a small-scale airplane wing comprised of an airfoil and wing tip boom as shown in Fig. 3, based on the ATW1 design. This wing was formulated based on a NACA65A004 airfoil shape with a 3.28 aspect ratio. The wing had a half span of $18 \mathrm{in}$. with root chord length of $13.2 \mathrm{in}$. and tip chord length of $8.7 \mathrm{in}$. The total area of this wing was $197 \mathrm{in}^{2}$. The wing tip boom was a 1 -in. diameter hollow tube of $21.5 \mathrm{in}$. length. The total weight of the wing was $2.66 \mathrm{lb}$. 


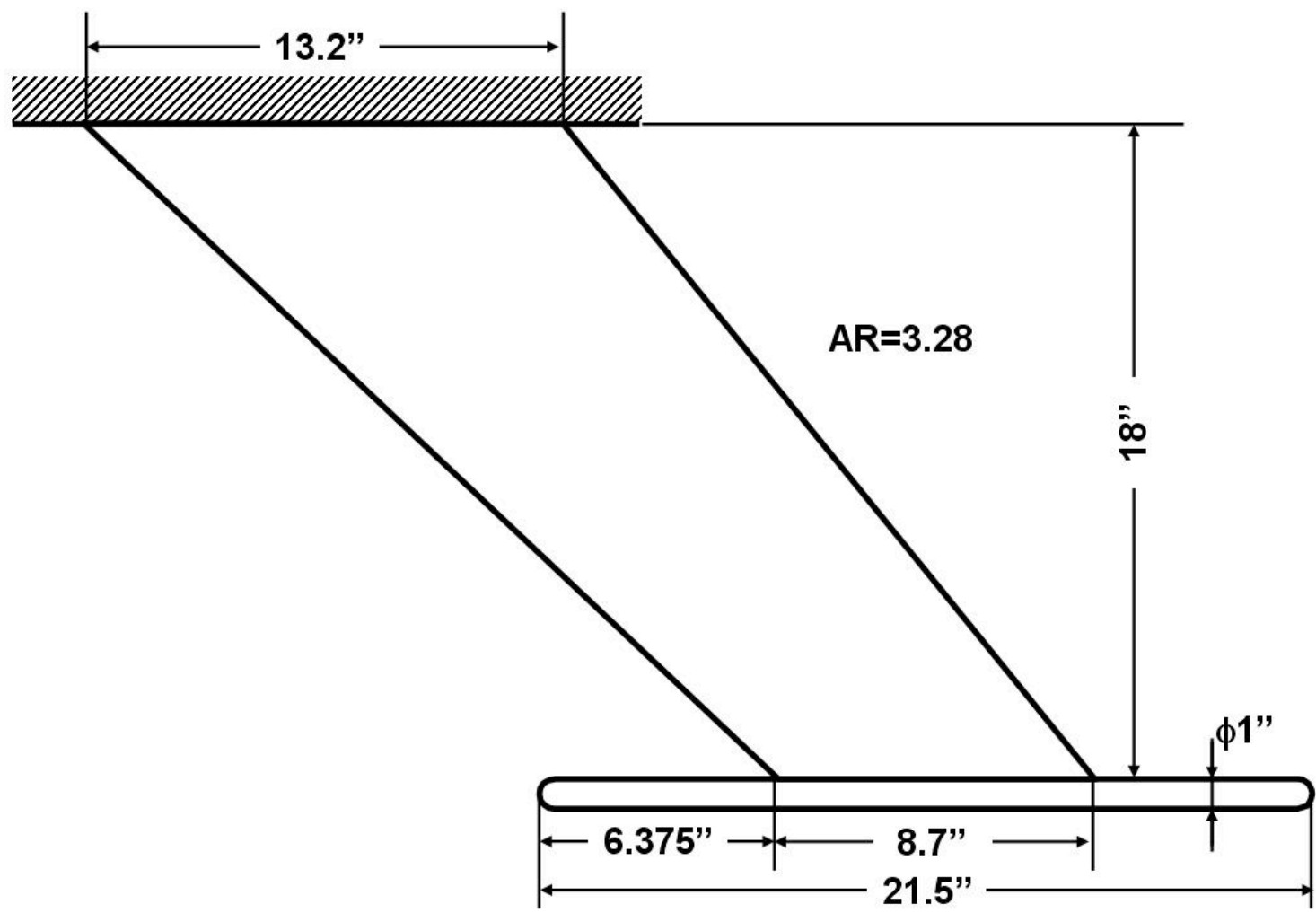

Figure 3. Dimension of the ATW2.

Since the ATW was attached to the F15B flight test fixture, the construction of the wing was limited to lightweight materials with no metal, due to safety concerns. The wing and spar were constructed from fiberglass cloth, the boom was constructed from carbon fiber composite, the wing core was constructed from rigid foam, and the components were attached by epoxy. The wing skin was made of three plies of fiberglass cloth, each about 0.01 in. thick. The internal spar located at the $30 \%$ chord line was composed of 10 plies, 0.05 in. thick of carbon at the root but decreases to 1 ply, 0.005 in. thick at the tip.

\section{Test Setup}

Ground vibration tests were performed to determine the dynamic modal characteristics of the ATW2. In the test set up, the ATW2 was clamped on to a circular plate, which was bolted to a mounting panel, and then installed into a small strong back called the ground test fixture in the NASA Dryden Flight Loads Laboratory. The PONTOS photogrammetry optical measuring system (Gesellschaft für Optische Messtechnik, Braunschweig, Germany), as shown in Fig. 4, was used to measure output displacement/acceleration at the sensor points. For the excitation method, an impact hammer with an impedance head was used to excite the ATW2's natural frequencies and mode shapes as well as to measure input forces. 


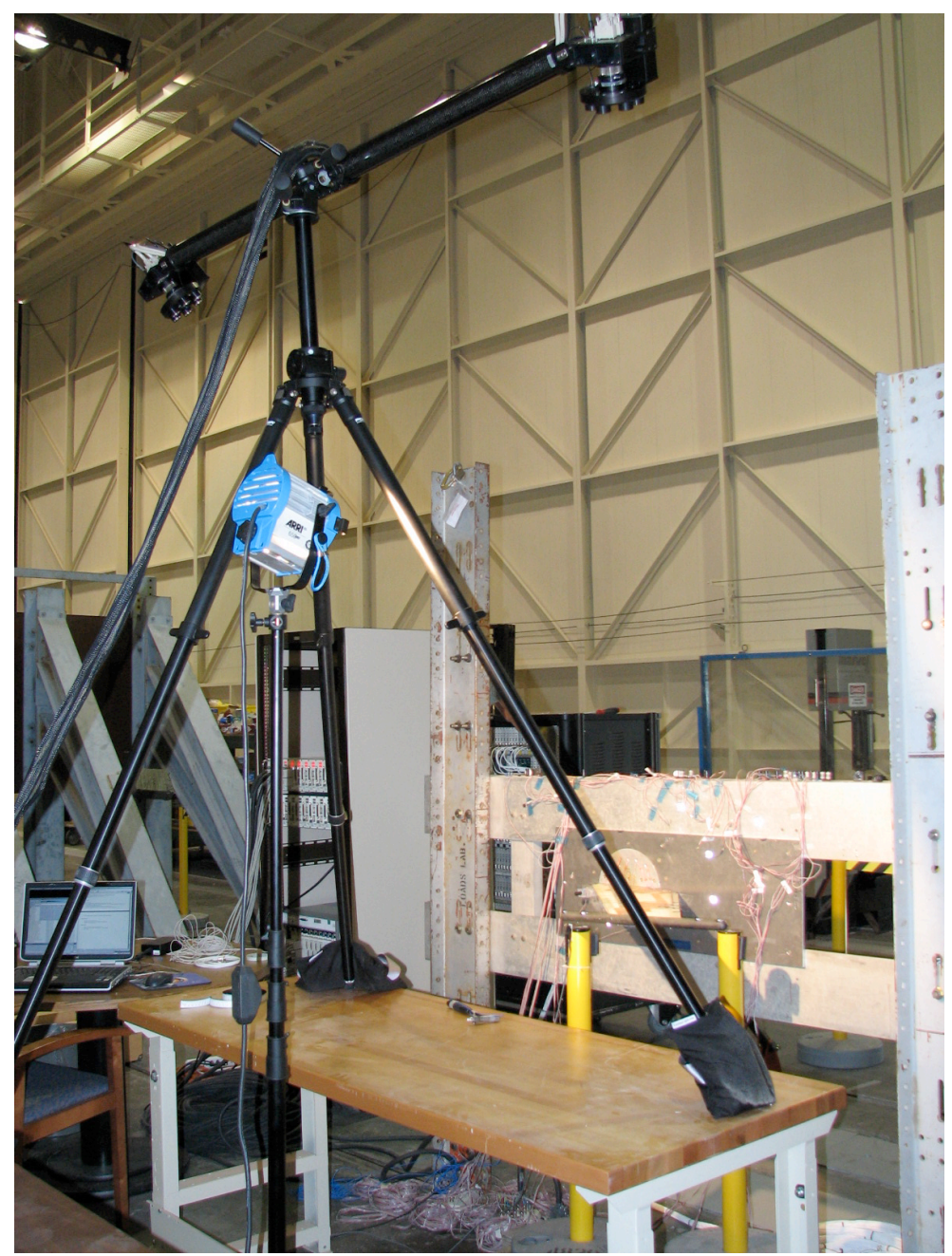

Figure 4. The PONTOS photogrammetry optical measuring system.

PONTOS is a non-contact optical 3D measuring system. It analyzes, computes and documents object deformations, rigid body movements and the dynamic behavior of a measuring point. ${ }^{16}$ The PONTOS system provides an alternative for complex sensor technology like laser sensor, draw-wire sensors or accelerometers, which are commonly used in GVTs for measuring responses of the structure. The features of the PONTOS system include:

1) Unlimited number of sensors (the sensor markers are weightless, and a large number of sensors can be used at the same time without altering the total weight or the mode shapes of the structure)

2) Non-contact acquisition of the precise 3D position of any number of measuring points

3) Mobility and flexibility due to an easy and compact measuring system

4) Easy and quick adaptation to different measuring volumes and measuring tasks

The limitations of the PONTOS system include:

1) Measuring structural vibration up to $250 \mathrm{~Hz}$

2) Measuring frame rate up to $500 \mathrm{~Hz}$ at $1280 \times 1024$ pixels

3) Measuring volume up to $1700 \times 1360 \times 1360 \mathrm{~mm}^{3}$

4) Applying the sensors on a plane or slightly curved surface 


\section{Sensor Placement Discussion}

Only a small number of sensors were placed on the wing for the GVT compared to the full FE model DOFs. The selection of sensor locations were based on the sensor placement algorithms previously discussed in Section II. In order to compare different sensor placement algorithms, the determinant of FIM was calculated for different sets of sensor locations. Results are summarized in Table 1 and the corresponding sensor locations are shown in Fig. 5.

Table 1. Comparison of the determinant of FIM for different sensor placement algorithm.

\begin{tabular}{|l|c|}
\hline Sensor placement algorithms & $\operatorname{det}($ FIM) (30 sensors, 3 modes) \\
\hline Effective independence & 753.1 \\
\hline Genetic algorithm & 753.1 \\
\hline Kinetic energy & 303.6 \\
\hline Iterative Guyan reduction & 59.5 \\
\hline Non-iterative Guyan reduction & 8.6 \\
\hline Model configuration (25 sensors) & 50.0 \\
\hline Driving point residue & 97.0 \\
\hline
\end{tabular}

* Based on 150 populations and 500 generations

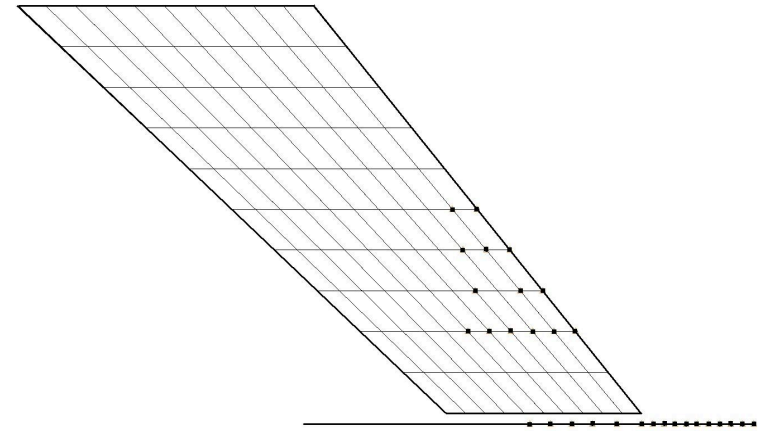

Figure 5a. DPR method.

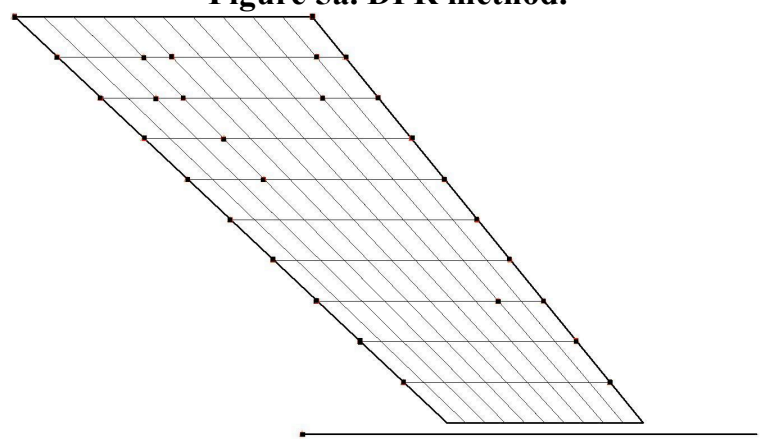

Figure 5c. Guyan reduction method.

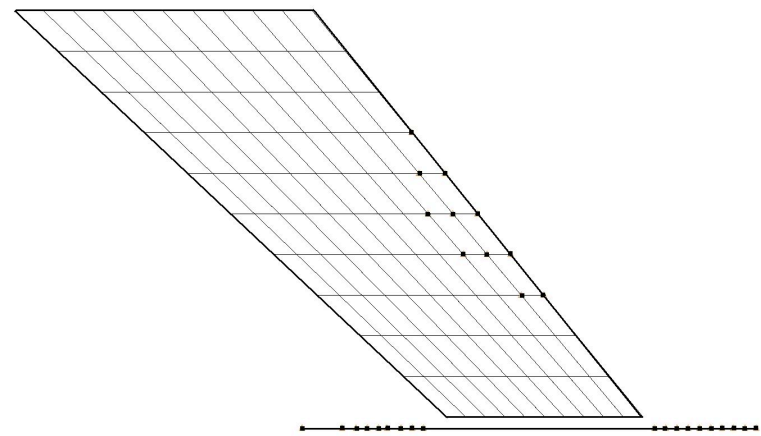

Figure 5e. Effective Independence method.

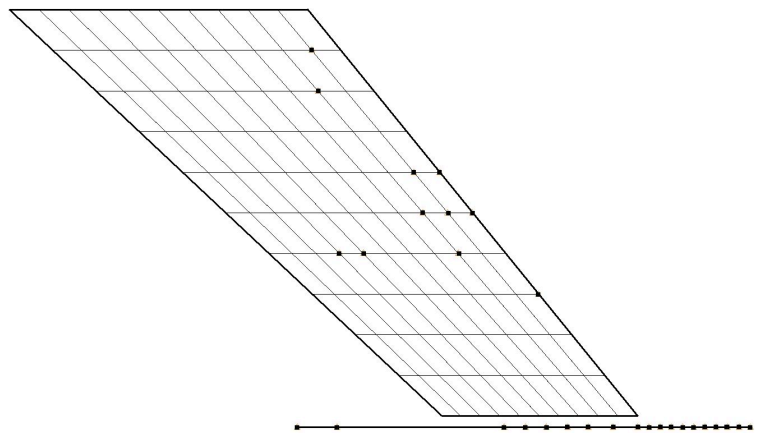

Figure 5b. KE method.

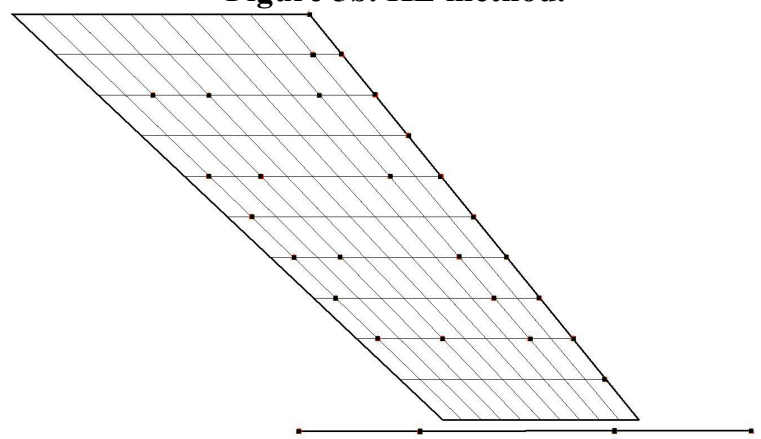

Figure 5d. Iterative Guyan Reduction method.

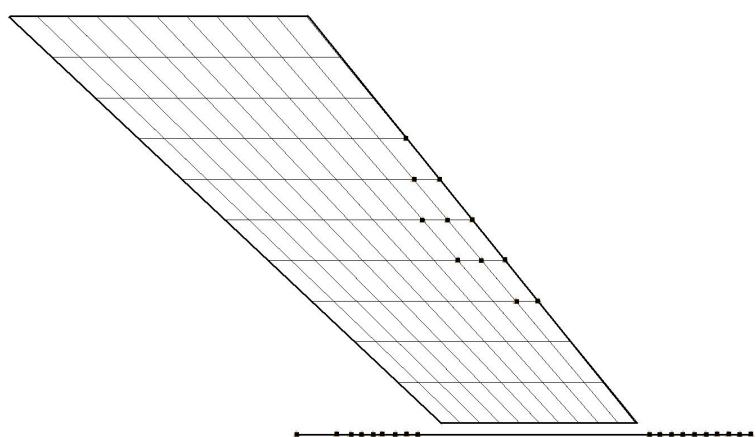

Figure 5f. Genetic Algorithm.

Figure 5. Sensor locations from different sensor placement algorithms.

10

American Institute of Aeronautics and Astronautics 
In Table 1 the EI and GA methods have the same determinant of FIM value. This is due to the fact that the EI method is also an optimization process. In this application, both the EI and GA methods found the globally optimal value. The sensor locations with higher determent of FIM value were used for the GVT response measurement locations.

For the excitation point selection, the weighted maximum driving point residue method was used to determine the excitation locations. The predicted sensor locations and excitation point based on the FE model of the ATW2 is shown in Fig. 6 and the corresponding coordinates are given in Table 2.

At the time of this ATW2 research work, only the GVT results with the sensor placements based on the model configuration were available. Therefore, these data were used for the FE model tuning process. The sensor locations and excitation point of this GVT are shown in Fig. 7, and its coordinates are listed in Table 3. Figure 8 shows the typical time history and frequency response curves of the ATW2 ground vibration tests.

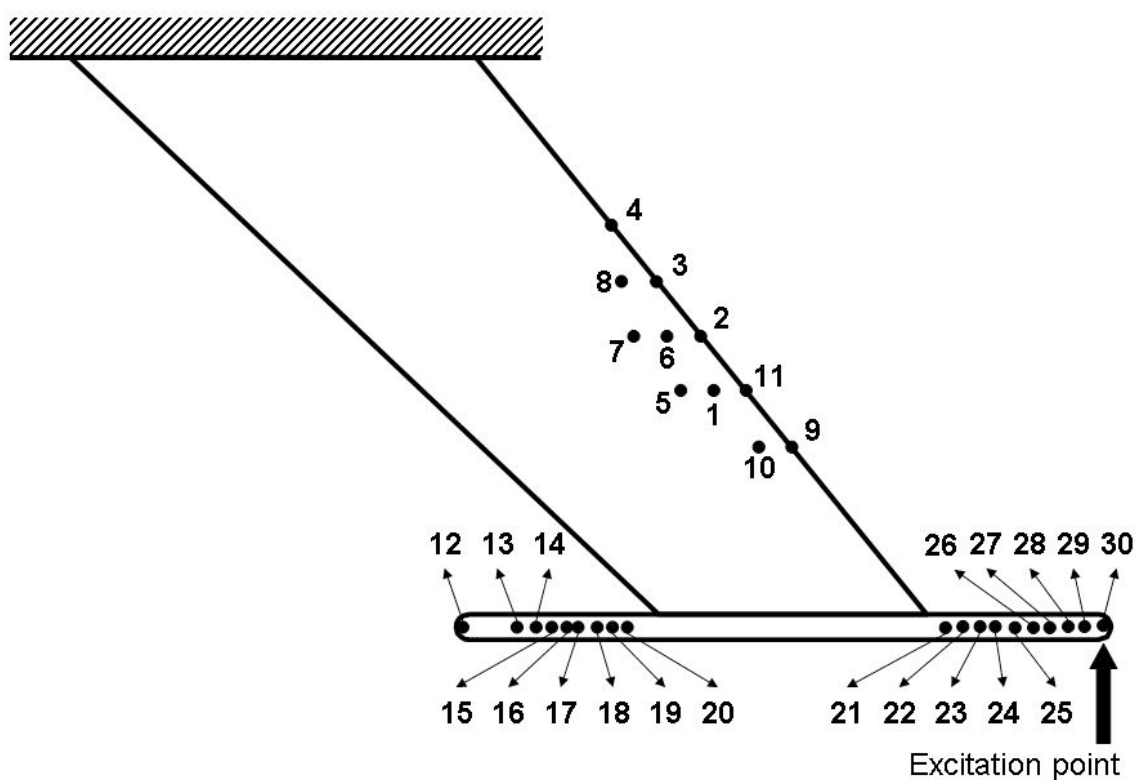

Figure 6. Predicted sensor/excitation locations.

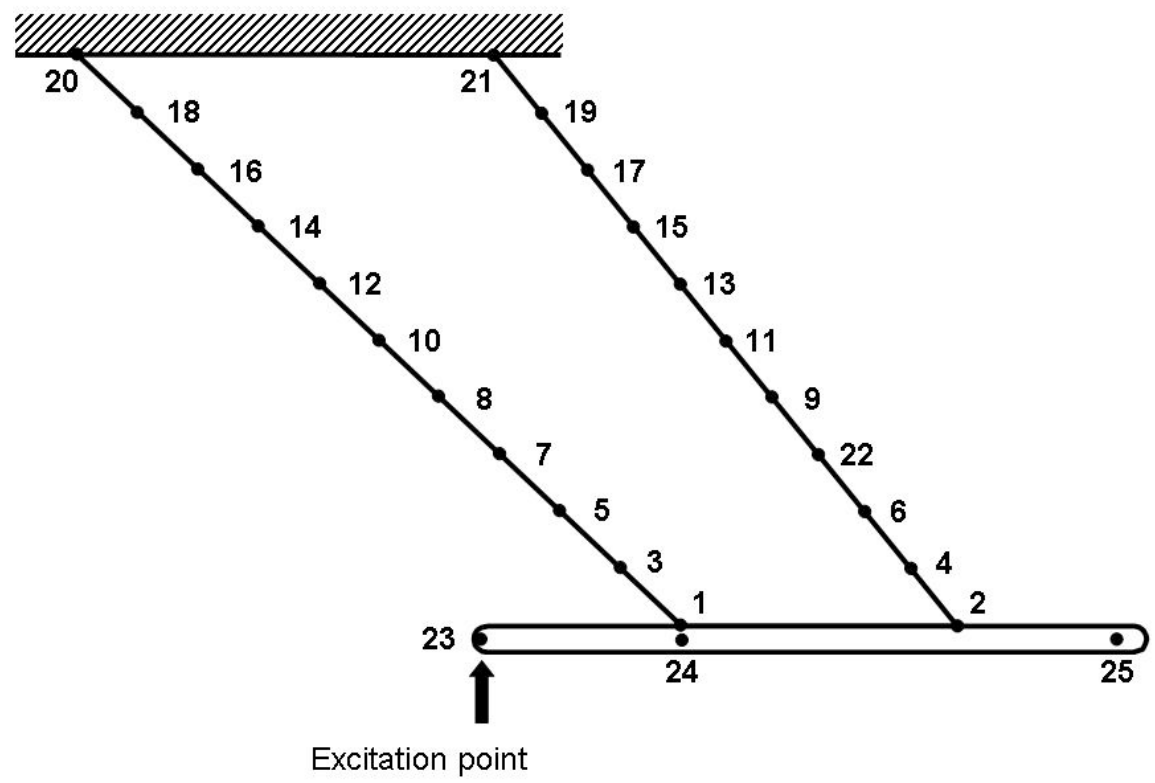

Figure 7. GVT sensor/excitation locations. 
Table 2. Sensor locations for Figure 6.

\begin{tabular}{|c|c|c|c|}
\hline \multirow{2}{*}{$\begin{array}{c}\text { Sensor } \\
\text { point }\end{array}$} & \multicolumn{3}{|c|}{ Coordinates (inch) } \\
\cline { 2 - 4 } $\mathbf{1}$ & 20.9244 & -10.80 & -0.05 \\
\hline $\mathbf{2}$ & 21.9750 & -10.80 & 0 \\
\hline $\mathbf{3}$ & 19.0499 & -7.20 & 0 \\
\hline $\mathbf{4}$ & 17.5875 & -5.40 & -0.001 \\
\hline $\mathbf{5}$ & 19.8735 & -10.80 & 0.1016 \\
\hline $\mathbf{6}$ & 19.4167 & -9.00 & 0.0537 \\
\hline $\mathbf{7}$ & 18.3209 & -9.00 & 0.1059 \\
\hline $\mathbf{8}$ & 17.9092 & -7.20 & 0.0559 \\
\hline $\mathbf{9}$ & 23.4375 & -12.60 & 0 \\
\hline $\mathbf{1 0}$ & 22.4317 & -12.60 & 0.0493 \\
\hline $\mathbf{1 1}$ & 21.9750 & -10.80 & 0 \\
\hline $\mathbf{1 2}$ & 12.7500 & -18.50 & 0 \\
\hline $\mathbf{1 3}$ & 14.5000 & -18.50 & 0 \\
\hline $\mathbf{1 4}$ & 15.1250 & -18.50 & 0 \\
\hline $\mathbf{1 5}$ & 15.6250 & -18.50 & 0 \\
\hline $\mathbf{1 6}$ & 16.1250 & -18.50 & 0 \\
\hline $\mathbf{1 7}$ & 16.5000 & -18.50 & 0 \\
\hline $\mathbf{1 8}$ & 17.1250 & -18.50 & 0 \\
\hline $\mathbf{1 9}$ & 17.6250 & -18.50 & 0 \\
\hline $\mathbf{2 0}$ & 18.1250 & -18.50 & 0 \\
\hline $\mathbf{2 1}$ & 28.3250 & -18.50 & 0 \\
\hline $\mathbf{2 2}$ & 28.8250 & -18.50 & 0 \\
\hline $\mathbf{2 3}$ & 29.3250 & -18.50 & 0 \\
\hline $\mathbf{2 4}$ & 29.8250 & -18.50 & 0 \\
\hline $\mathbf{2 5}$ & 30.3250 & -18.50 & 0 \\
\hline $\mathbf{2 6}$ & 30.8250 & -18.50 & 0 \\
\hline $\mathbf{2 7}$ & 31.3250 & -18.50 & 0 \\
\hline $\mathbf{2 8}$ & 31.8250 & -18.50 & 0 \\
\hline $\mathbf{2 9}$ & 32.3250 & -18.50 & 0 \\
\hline $\mathbf{3 0}$ & 32.8250 & -18.50 & 0 \\
\hline & & & \\
\hline
\end{tabular}

Table 3. Sensor locations for Figure 7.

\begin{tabular}{|c|c|c|c|}
\hline \multirow{2}{*}{$\begin{array}{c}\text { Sensor } \\
\text { point }\end{array}$} & \multicolumn{3}{|c|}{ Coordinates (inch) } \\
\cline { 2 - 4 } $\mathbf{1}$ & 19.125 & -18.00 & $\mathbf{Z}$ \\
\hline $\mathbf{2}$ & 27.825 & -18.00 & 0 \\
\hline $\mathbf{3}$ & 17.212 & -16.20 & 0 \\
\hline $\mathbf{4}$ & 26.362 & -16.20 & 0 \\
\hline $\mathbf{5}$ & 15.300 & -14.40 & 0 \\
\hline $\mathbf{6}$ & 24.900 & -14.40 & 0 \\
\hline $\mathbf{7}$ & 13.387 & -12.56 & 0 \\
\hline $\mathbf{8}$ & 11.475 & -10.80 & 0 \\
\hline $\mathbf{9}$ & 21.975 & -10.80 & 0 \\
\hline $\mathbf{1 0}$ & 9.5625 & -9.00 & 0 \\
\hline $\mathbf{1 1}$ & 20.5125 & -9.0 & 0 \\
\hline $\mathbf{1 2}$ & 7.65 & -7.2 & 0 \\
\hline $\mathbf{1 3}$ & 19.0499 & -7.2 & 0 \\
\hline $\mathbf{1 4}$ & 5.7375 & -5.4 & 0 \\
\hline $\mathbf{1 5}$ & 17.5875 & -5.4 & 0 \\
\hline $\mathbf{1 6}$ & 3.825 & -3.6 & 0 \\
\hline $\mathbf{1 7}$ & 16.125 & -3.6 & 0 \\
\hline $\mathbf{1 8}$ & 1.9125 & -1.8 & 0 \\
\hline $\mathbf{1 9}$ & 14.6625 & -1.8 & 0 \\
\hline $\mathbf{2 0}$ & 0 & 0 & 0 \\
\hline $\mathbf{2 1}$ & 13.2 & 0 & 0 \\
\hline $\mathbf{2 2}$ & 23.4375 & -12.6 & 0 \\
\hline $\mathbf{2 3}$ & 12.75 & -18.5 & 0 \\
\hline $\mathbf{2 4}$ & 19.125 & -18.5 & 0 \\
\hline $\mathbf{2 5}$ & 32.825 & -18.5 & 0 \\
\hline & & & \\
\hline
\end{tabular}



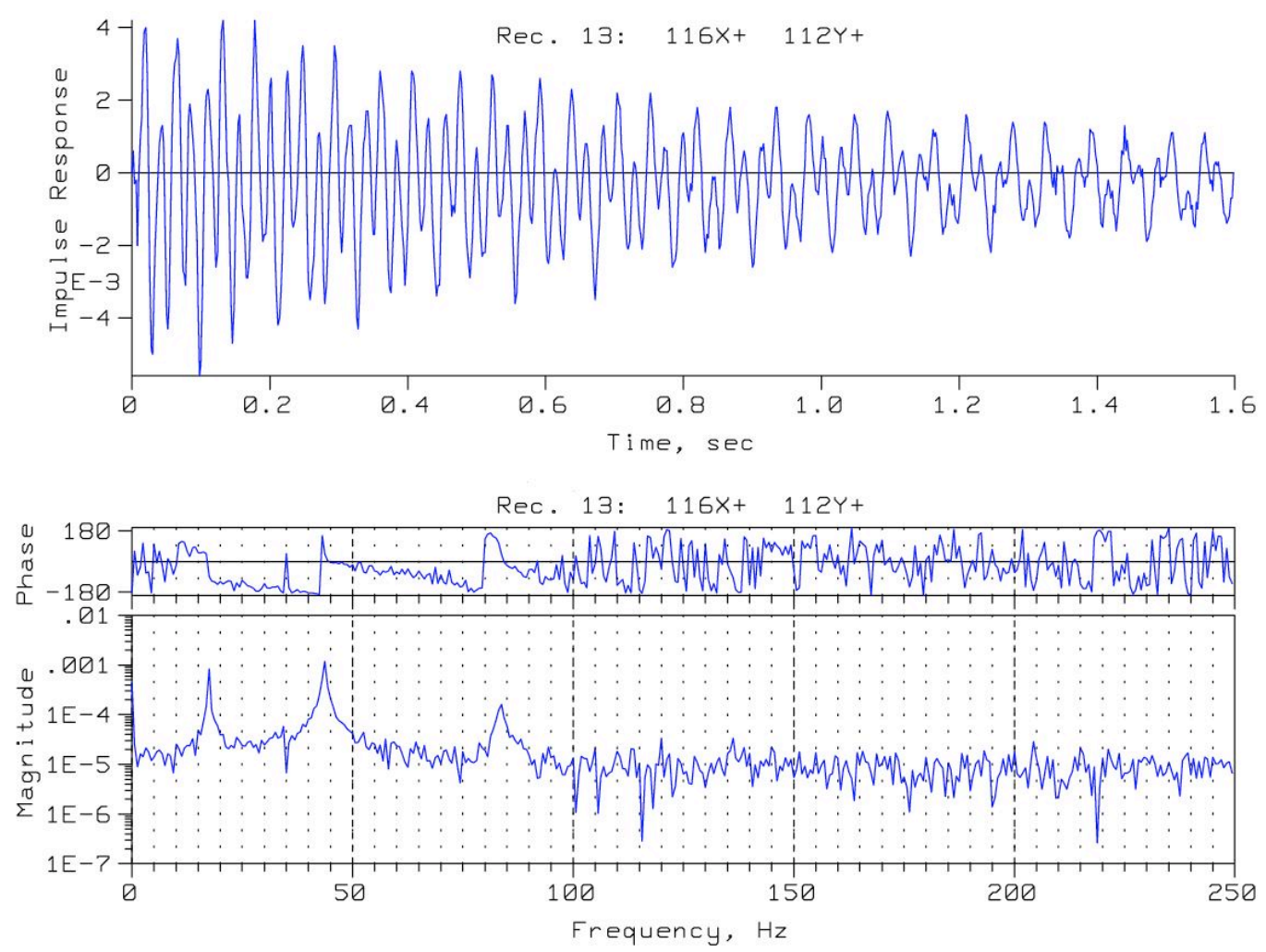

Figure 8. Typical time history and frequency response GVT results for the ATW2.

\section{Model Tuning}

The frequencies and mode shapes of first bending, first torsion and second bending modes; and total mass from the GVT are listed in Table 4. The measurements of Table 4 were based on the time history responses data collected by the PONTOS system at each of the sensor points. The eigensystem realization algorithm routine, which was developed by Juang and Pappa ${ }^{17}$ at NASA Langley Research Center (LaRC) (Hampton, Virginia) was then used to identify the frequencies and mode shapes of the system. 
Table 4. Measured frequencies and mode shapes ( $\mathrm{Z}$ direction).

\begin{tabular}{|c|c|c|c|}
\hline $\begin{array}{c}\text { Sensor } \\
\text { point }\end{array}$ & $\begin{array}{c}\text { Mode 1 } \\
(17.24 \mathrm{~Hz})\end{array}$ & $\begin{array}{c}\text { Mode } 2 \\
(44.10 \mathrm{~Hz})\end{array}$ & $\begin{array}{c}\text { Mode } 3 \\
(\mathbf{8 4 . 0 0} \mathrm{Hz}) \\
\end{array}$ \\
\hline 1 & 0.481 & -0.398 & -0.325 \\
\hline 2 & 0.755 & 0.409 & -0.187 \\
\hline 3 & 0.386 & -0.390 & -0.149 \\
\hline 4 & 0.670 & 0.353 & 0.142 \\
\hline 5 & 0.311 & -0.408 & 0.088 \\
\hline 6 & 0.589 & 0.254 & 0.455 \\
\hline 7 & 0.214 & -0.320 & 0.113 \\
\hline 8 & 0.139 & -0.252 & 0.157 \\
\hline 9 & 0.368 & 0.082 & 0.912 \\
\hline 10 & 0.085 & -0.177 & 0.131 \\
\hline 11 & 0.281 & 0.036 & 1.000 \\
\hline 12 & 0.047 & -0.116 & 0.140 \\
\hline 13 & 0.196 & 0.021 & 0.917 \\
\hline 14 & 0.018 & -0.067 & 0.053 \\
\hline 15 & 0.157 & 0.018 & 0.870 \\
\hline 16 & 0.006 & 0.022 & -0.012 \\
\hline 17 & 0.081 & 0.026 & 0.587 \\
\hline 18 & 0.008 & 0.007 & 0.006 \\
\hline 19 & 0.035 & 0.025 & 0.345 \\
\hline 20 & 0.010 & 0.008 & 0.017 \\
\hline 21 & 0.014 & 0.022 & 0.125 \\
\hline 22 & 0.451 & -0.111 & 0.765 \\
\hline 23 & 0.312 & -1.000 & -0.582 \\
\hline 24 & 0.518 & -0.432 & -0.523 \\
\hline 25 & 1.000 & 0.962 & -0.196 \\
\hline
\end{tabular}

Corresponding numerical FE model frequencies and mode shapes computed using MSC/NASTRAN (MSC. Software Corporation, Santa Ana, California) ${ }^{18}$ are shown in Fig. 9. The FE model in the MSC/NASTRAN format is provided in the appendix of NASA/TM-2009-214646. The frequency differences between the GVT and the numerical results before model tuning (shown in Table 5) were 53\% in the second mode and $12 \%$ in the third mode, both of which greatly exceed the 3\% limitation for the primary modes allowed by military specifications. ${ }^{19,} 20$ Therefore, the FE model needs to be updated for a more reliable flutter analysis. 


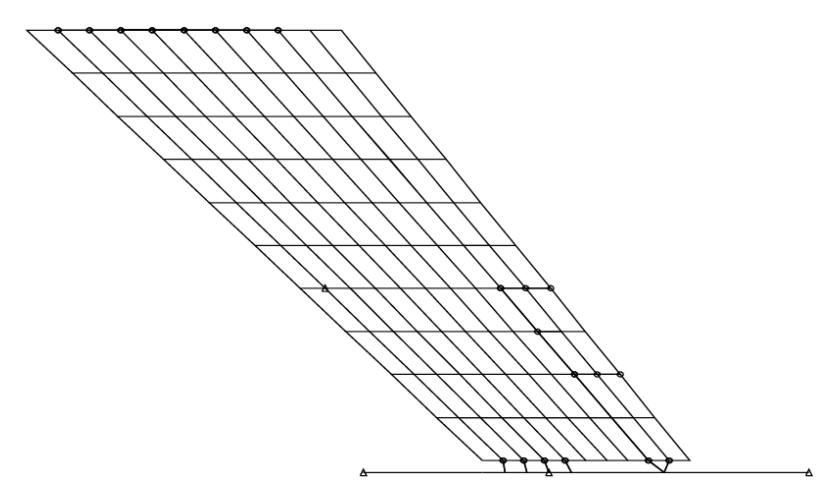

Figure 9a. MSC/NASTRAN FE Model

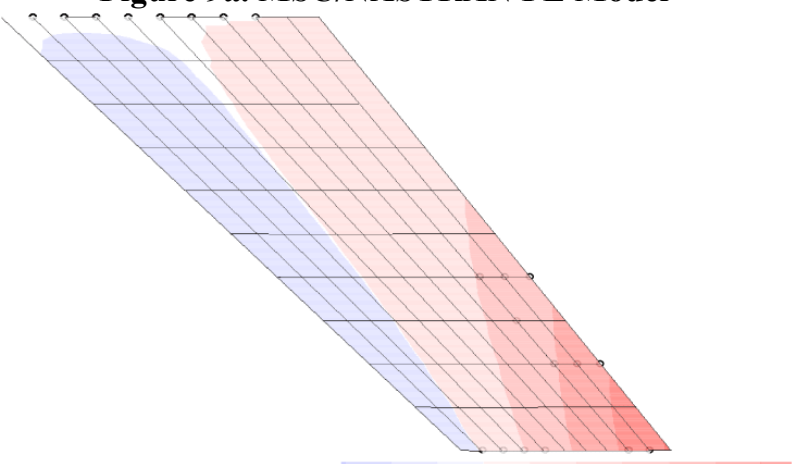

Figure 9c. Mode $2\left(1^{\text {st }}\right.$ torsion): $20.9207 \mathrm{~Hz}$.

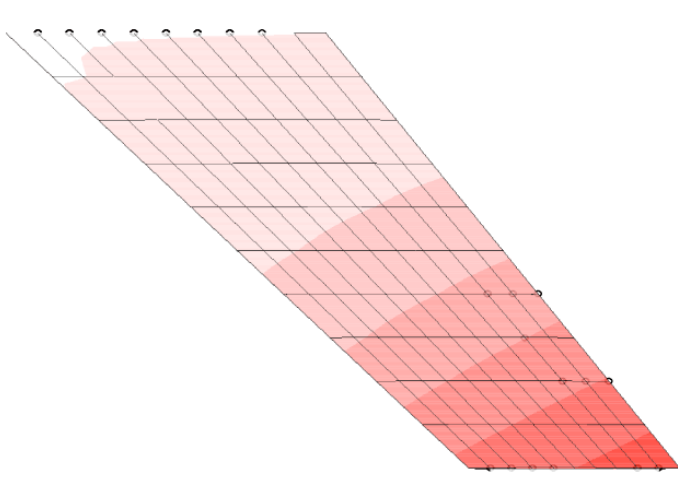

Figure 9b. Mode 1 ( ${ }^{\text {st }}$ bending): $17.7048 \mathrm{~Hz}$.

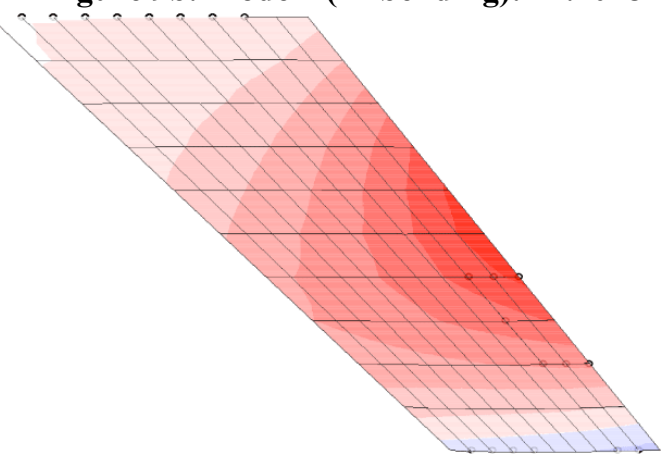

Figure 9d. Mode 3 ( $2^{\text {nd }}$ bending): $88.3203 \mathrm{~Hz}$.

Figure 9. Finite element model and mode shapes before tuning.

Table 5. Frequencies and total weight of the ATW2 before and after model tuning.

\begin{tabular}{|c|c|c|c|c|c|}
\hline & \multirow{2}{*}{$\begin{array}{c}\text { GVT } \\
\end{array}$} & \multicolumn{2}{|c|}{ Before } & \multicolumn{3}{c|}{ After } \\
\cline { 3 - 7 } & $(\mathrm{Hz})$ & $\begin{array}{c}\text { MSC/NASTRAN } \\
(\text { Guyan/Full; Hz) }\end{array}$ & Error (\%) & $\begin{array}{c}\text { MSC/NASTRAN } \\
(\text { SEREP/Full; Hz) }\end{array}$ & Error $(\%)$ \\
\hline Mode 1 & 17.24 & $17.71 / 17.70$ & $2.72 / 2.68$ & $17.79 / 17.79$ & $3.19 / 3.19$ \\
\hline Mode 2 & 44.10 & $20.93 / 20.92$ & $-52.5 /-52.6$ & $44.71 / 44.71$ & $1.38 / 1.38$ \\
\hline Mode 3 & 84.00 & $93.91 / 88.32$ & $11.80 / 5.14$ & $84.33 / 84.33$ & $0.39 / 0.39$ \\
\hline Total weight (lb) & 2.66 & 2.77 & 4.13 & 2.72 & 2.25 \\
\hline
\end{tabular}

Since Guyan reduction is a static condensation, it is only accurate for lower modes. For higher modes, the errors become too large as shown in Table 5. Unlike the Guyan reduction, the SEREP process preserves the dynamic character of the original full system model for selected modes of interest. Therefore the dynamic characteristics of the reduced model were virtually the same as the full model shown in Table 5. Therefore, the SEREP model reduction process was used in this ATW2 model update application.

Using frequency difference as an objective function; and mass properties, mass orthogonality, and mode shapes as constraint equations; the frequencies before and after model tuning are presented in Table 5. Dramatic improvement was noted, in that after model tuning, the frequencies difference was reduced to $1.38 \%$ in the second mode and $0.39 \%$ in the third mode.

Table 6 shows the center of gravity, moment of inertia, orthonormalized mass matrix, and modal assurance criterion (MAC) values of the ATW2 before and after model tuning. The off-diagonal terms of the orthonormalized mass matrix, maximum of $37 \%$ before model tuning, were minimized in the second tuning step. The maximum offdiagonal term of $7.4 \%$ after model tuning is observed in table 6 , and this off-diagonal term of the orthonormalized mass matrix satisfies the $10 \%$ limitation allowed by military specifications. Model correlation with the test data prior to model tuning was poor and unacceptable to proceed with flight. The MAC values of 0.52 and 0.73 for modes 2 
and 3 before model tuning become 0.97 and 0.95 , respectively. Therefore, we can conclude that excellent model correlation with the test data was achieved after model tuning, which lead to a more reliable flutter speed prediction.

Table 6. Summary of center of gravity, moment of inertia, orthonormalized mass matrix and MAC values for the ATW2 before and after model tuning.

\begin{tabular}{|c|c|c|c|c|c|c|c|c|}
\hline & & & \multicolumn{3}{|c|}{ Before tuning } & \multicolumn{3}{|c|}{ After tuning } \\
\hline \multicolumn{3}{|c|}{ C.G. $(X, Y, Z)$} & \multicolumn{3}{|c|}{$14.22,-11.86,-0.011$} & \multicolumn{3}{|c|}{$13.089,-7.61,-0.0080$} \\
\hline \multicolumn{3}{|c|}{ Ixx } & \multicolumn{3}{|c|}{73.44} & \multicolumn{3}{|c|}{97.52} \\
\hline \multicolumn{3}{|c|}{ Iyy } & \multicolumn{3}{|c|}{74.74} & \multicolumn{3}{|c|}{118.13} \\
\hline \multicolumn{3}{|c|}{ Izz } & \multicolumn{3}{|c|}{148.1} & \multicolumn{3}{|c|}{215.5} \\
\hline \multicolumn{3}{|c|}{ Ixy } & \multicolumn{3}{|c|}{-43.03} & \multicolumn{3}{|c|}{-85.55} \\
\hline \multicolumn{3}{|c|}{ Ixz } & \multicolumn{3}{|c|}{0.032} & \multicolumn{3}{|c|}{0.0286} \\
\hline \multicolumn{3}{|c|}{ Iyz } & \multicolumn{3}{|c|}{-0.02} & \multicolumn{3}{|c|}{0.0956} \\
\hline \multirow{4}{*}{\multicolumn{2}{|c|}{ Orthonormalized mass matrix }} & & 1 & 2 & 3 & 1 & 2 & 3 \\
\hline & & 1 & 1 & $25.0 \%$ & $4.6 \%$ & 1 & $4.0 \%$ & $-5.7 \%$ \\
\hline & & 2 & 0.2467 & 1 & $37.0 \%$ & 0.0395 & 1 & $-7.4 \%$ \\
\hline & & 3 & 0.0463 & 0.3681 & 1 & -0.0565 & -0.0743 & 1 \\
\hline \multirow{3}{*}{ MAC } & \multicolumn{2}{|c|}{ Mode 1} & \multicolumn{3}{|c|}{0.90} & \multicolumn{3}{|c|}{0.99} \\
\hline & \multirow{2}{*}{\multicolumn{2}{|c|}{ Mode 2}} & \multirow{2}{*}{\multicolumn{3}{|c|}{$\frac{0.52}{0.73}$}} & \multirow{2}{*}{\multicolumn{3}{|c|}{$\frac{0.97}{0.95}$}} \\
\hline & & Mode 3 & & & & & & \\
\hline
\end{tabular}

\section{Concluding Remarks}

This paper describes the ground vibration test (GVT) and model tuning procedures for the second aerostructures test wing (ATW2), which was developed at the National Aeronautics and Space Administration (NASA) Dryden Flight Research Center (DFRC) (Edwards, California) for demonstrating flutter and advanced aeroelastic test techniques. In the sensor locations selection process, it was found that the effective independence (EI) and the genetic algorithm (GA) gave a higher determinant value of the Fisher information matrix (FIM) and thus, should be used for determining the sensor locations.

The finite element (FE) model tuning process was a challenging task, which depended not only on the accuracy of the experimental data, but also required a good prediction of the design variables for the optimization. After tuning the FE model, the frequency differences between GVT and the numerical results were within 3\%, and the offdiagonal terms of the orthonormalized mass matrix were within $10 \%$, both of which satisfy the military specifications. Excellent mode shape correlations were also achieved through the high modal assurance criterion (MAC) value (greater than 95\%). With the updated FE model, the accuracy of flutter analysis can be improved and the flutter boundary prediction will be more reliable.

\section{Acknowledgement}

The authors would like to acknowledge the assistance of Claudia Herrara, Matt Moholt and Starr Ginn at NASA Dryden Flight Research Center in the setting and performing of the ground vibration tests.

\section{References}

${ }^{1}$ Lind, R., Voracek, D., Truax, R., Doyle, T., Potter, S., and Brenner, M., "A Flight Test to Demonstrate Flutter and Evaluate the Flutterometer," The Aeronautical Journal, Vol. 107, No. 1076, October 2003, pp. 577 - 588.

${ }^{2}$ Pak, C., and Li, W., "Multidisciplinary Design, Analysis, and Optimization Tool Development Using a Genetic Algorithm," Proceedings of the $26^{\text {th }}$ Congress of International Council of the Aeronautical Science, Anchorage, 2008.

${ }^{3}$ Kammer, D. C., "Sensor Placement for On-Orbit Modal Identification and Correlation of Large Space Structures," AIAA Journal of Guidance, Control and Dynamics, Vol. 14, No. 2, 1991, pp. 251-259.

${ }^{4}$ Charbonneau, P., and Knapp, B., A User's Guide to PIKAIA 1.0, National Center for Atmospheric Research, Boulder, CO, 1995.

${ }^{5}$ Friswell, M. I., and Mottershead, J. E., Finite Element Model Updating in Structural Dynamics, Kluwer Academic Publishers, Dordrecht, 1995.

${ }^{6}$ Guyan, R. J., "Reduction of stiffness and mass matrices," AIAA Journal, Vol. 3, No. 2, 1965, p. 380. 
7 Tinker, M. L., "Accelerometer Placement for the International Space Station Node Modal Test," AIAA-1998-2078, AIAA/ASME/ASCE/AHS/ASC Structures, Structural Dynamics, and Materials Conference and Exhibit, $39^{\text {th }}$ and AIAA/ASME/AHS Adaptive Structures Forum, Long Beach, CA, April 20-23, 1998.

${ }^{8}$ EI-Borgi, S., Neifar, M., Cherif, F., Choura, S., and Smaoui, H., "Modal Identification, Model Updating and Nonlinear Analysis of a Reinforced Concrete Bridge," Journal of Vibration and Control, Vol. 14, No. 4, 2008, pp. 511-530.

${ }^{9}$ Pak, C., "Finite Element Model Tuning Using Measured Mass Properties and Ground Vibration Test Data," ASME Journal of Vibration and Acoustics, Vol. 131, No. 1, February 2009.

${ }^{10}$ Lung, S., and Pak, C., "Structural Model Tuning Capability in an Object-Oriented Multidisciplinary Design, Analysis, and Optimization Tool," Proceedings of the $26^{\text {th }}$ Congress of International Council of the Aeronautical Sciences, Anchorage, 2008.

${ }^{11}$ Herrera, C., and Pak, C., "Build-up Approach to Updating the Mock Quiet Spike Beam Model," AIAA-2007-1776, Proceedings of the $48^{\text {th }}$ AIAA/ASME/ASCE/AHS/ASC Structures, Structural Dynamics, and Materials Conference, Honolulu, Hawaii, April 23-26, 2007.

12 Vanderplaats, G., Numerical Optimization Techniques for Engineering Design, $3^{\text {rd }}$ ed., Vanderplaats Research \& Development, Inc. 2001.

${ }^{13}$ Yeniay, Ö., "Penalty Function Methods For Constrained Optimization Using Genetic Algorithms," Mathematical and Computational Applications, Vol. 10, No. 1, 2005, pp. 45-56.

${ }^{14}$ O'Callahan, J. C., “A New Procedure for an Improved Reduced System (IRS) Model," Proceedings of the $7^{\text {th }}$ International Modal Analysis Conference, Vol. 1, Las Vegas, 1989, pp. 17-21.

${ }^{15}$ O'Callahan, J. C., Avitabile, P., and Riemer, R., "System Equivalent Reduction Expansion Process," Proceedings of the $7^{\text {th }}$ International Modal Analysis Conference, Vol. 1, Las Vegas, 1989, pp. 29-37.

${ }^{16}$ PONTOS User Manual Version 6.0. Gesellschaft für Optische Messtechnik, Braunschweig, Germany, 2007.

17 Juang, J. N., and Pappa, R. S., "An Eigensystem Realization Algorithm for Modal Parameter Identification and Modal Reduction," AIAA Journal of Guidance, Control, and Dynamics, Vol. 8, No. 5, 1984, pp. 620-627.

${ }^{18}$ Reymond, M., and Miller, M., MSC/NASTRAN Quick Reference Guide version 69, The MacNeal-Schwendler Corporation, 1996.

${ }^{19}$ Military Standard, Test Requirements for Launch, Upper-Stage, and Space Vehicles, MIL-STD-1540C Section 6.2.10, September 15, 1994.

${ }^{20}$ Norton, W. J., Structures Flight Test Handbook, AFFTC-TIH-90-001, November, 1990. 


\title{
Updating the Finite Element Model of the Aerostructures Test Wing Using Ground Vibration Test Data
}

\author{
Shun-fat Lung, Ph.D.* and Chan-gi Pak, Ph.D.** \\ *: Contractor, Tybrin Corporation \\ **: Group Leader
}




\section{Objectives}

- Support the Aeronautics Research Mission Directorate (ARMD) guidelines at NASA's Dryden Flight Research Center.

* Supported by Subsonic Fixed Wing (SFW) \& Supersonics (SUP) projects under Fundamental Aeronautics (FA) Program

- Reduce uncertainties in the structural dynamics model of the Aerostructures Test Wing 2 to increase the safety of flight

* Develop model update techniques based on design optimization to improve analysis/test correlation

\section{AEROSTRUCTURES TEST WING}
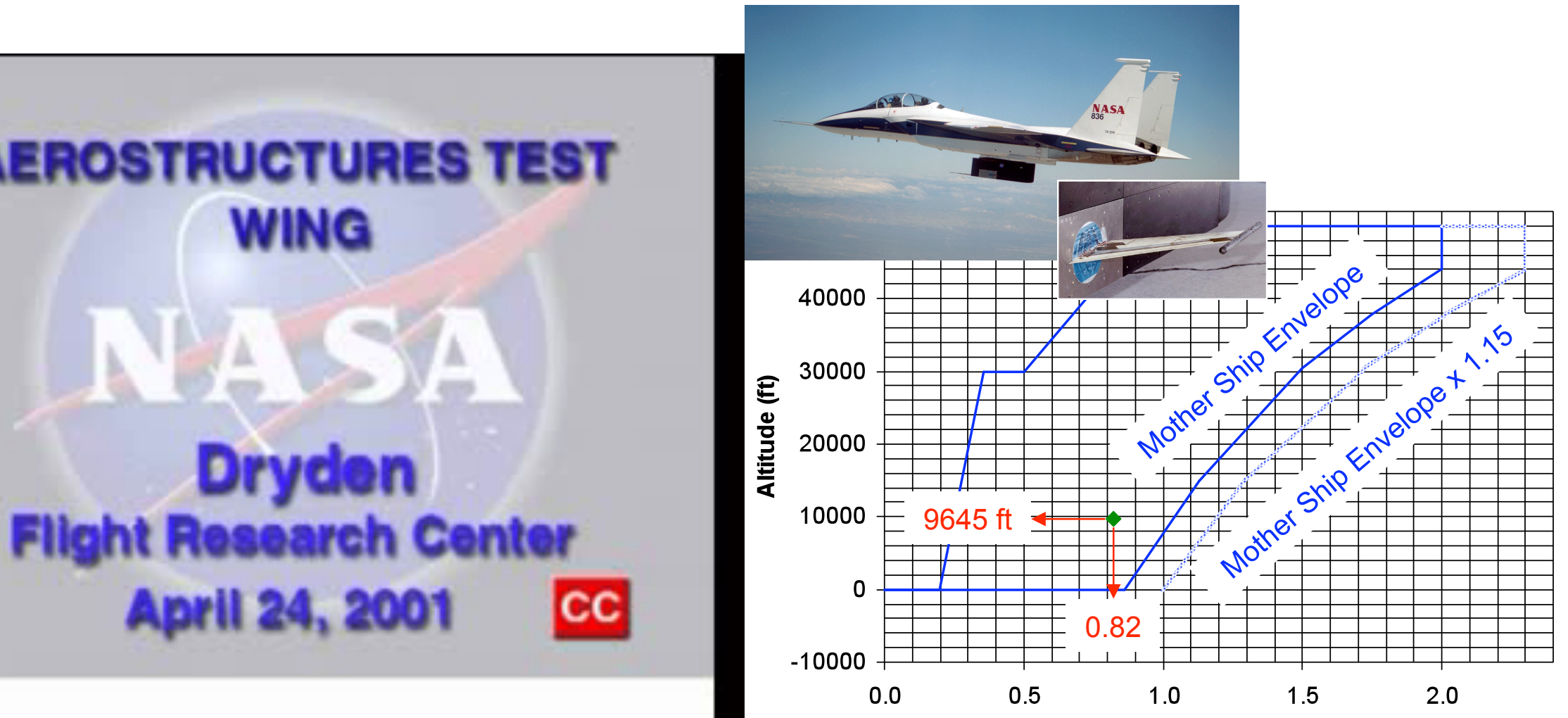


\section{Flutter Analysis Procedure@ NASA Dryden}

- Flutter Analysis

* Uncertainties in the structural dynamic model are minimized through the use of "model tuning technique"

Structural Dynamic

Finite Element Model

* Based on analytical modes

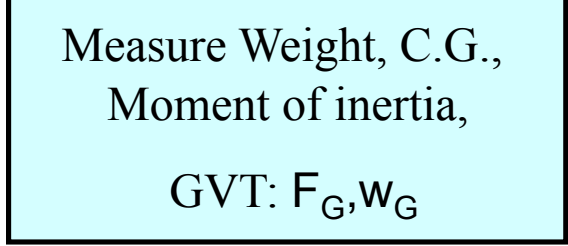

V Validate Structural Dynamic Finite Element Model using Test Data and Update if needed

* Use MDAO (Multidisciplinary Design, Analysis, and Optimization) tool with Model Tuning Capability or Standalone Model Tuning Code

$>$ Model tuning is based on optimization.

$\checkmark$ Design Variables

- Structural sizing information: Thickness, cross sectional area, area moment of inertia, etc.

- Point properties: lumped mass, spring constant, etc.

- Material properties: density, Young's modulus, etc.

$\checkmark$ Constraints
Validated

Finite Element Model

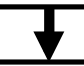

Create Unsteady Aerodynamic Model

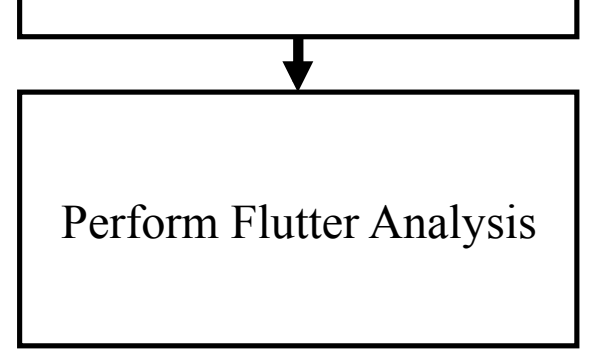




\section{Test Article: Exploded View of ATW 2}

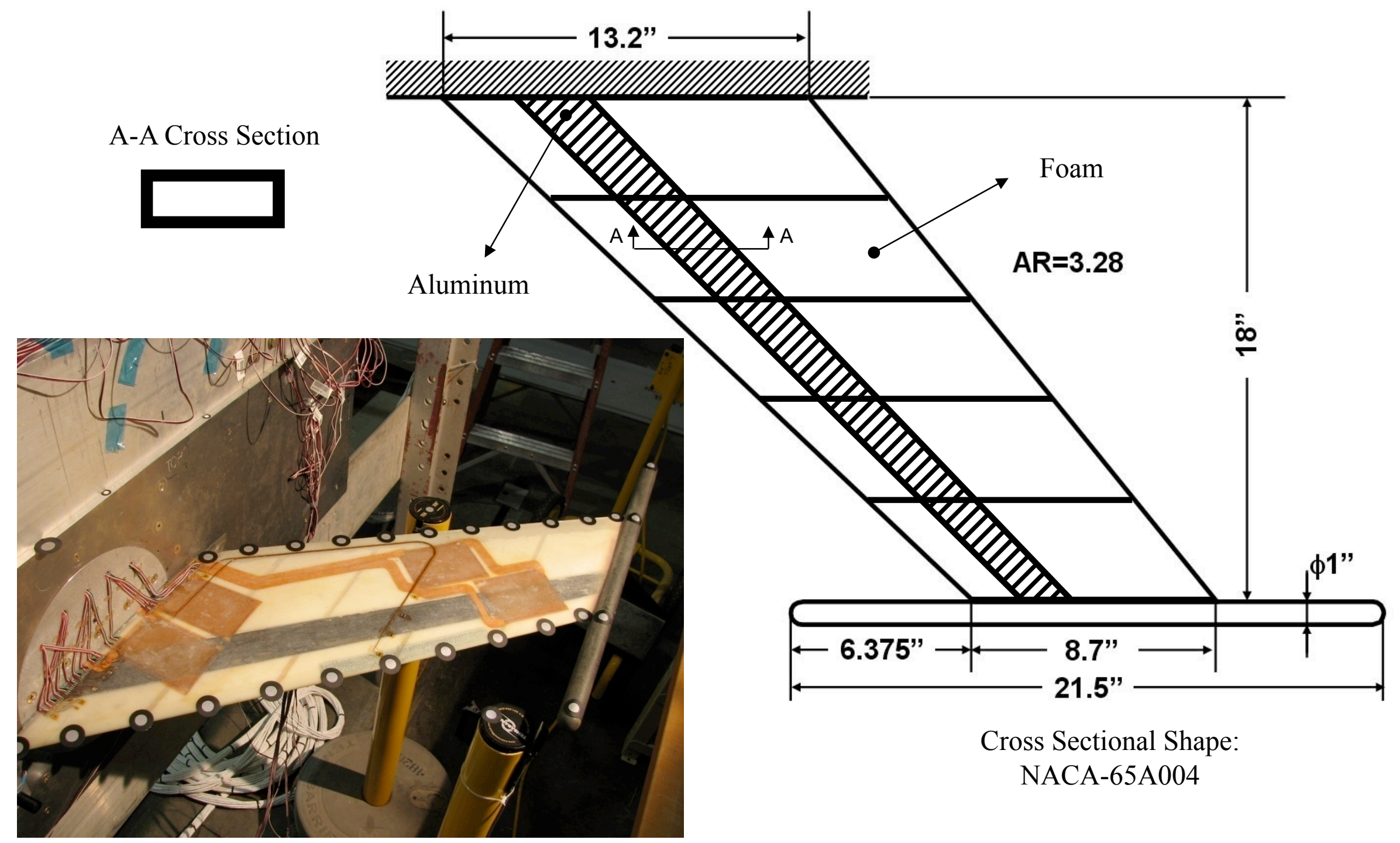




\section{Structural Dynamic Finite Element Model}

口 Based on MSC/NASTRAN code

* 265 nodes

- Use 10 modes for the flutter analysis

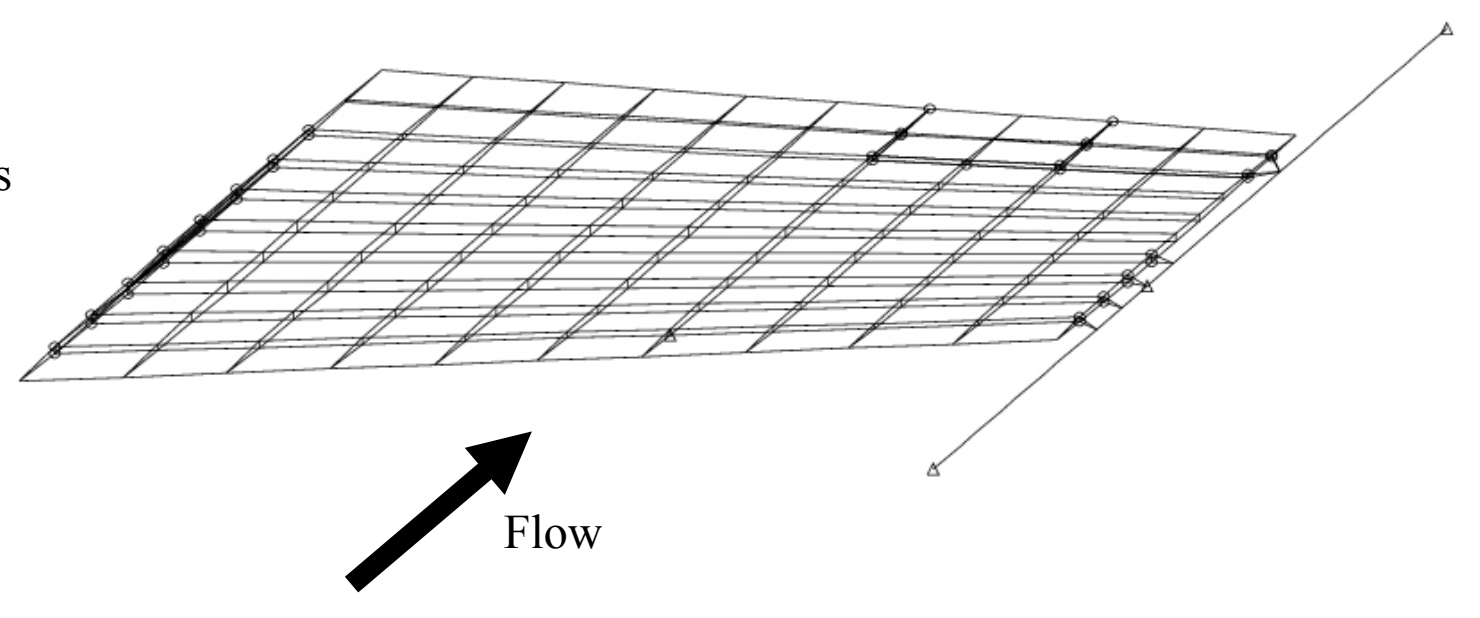

Boundary Conditions

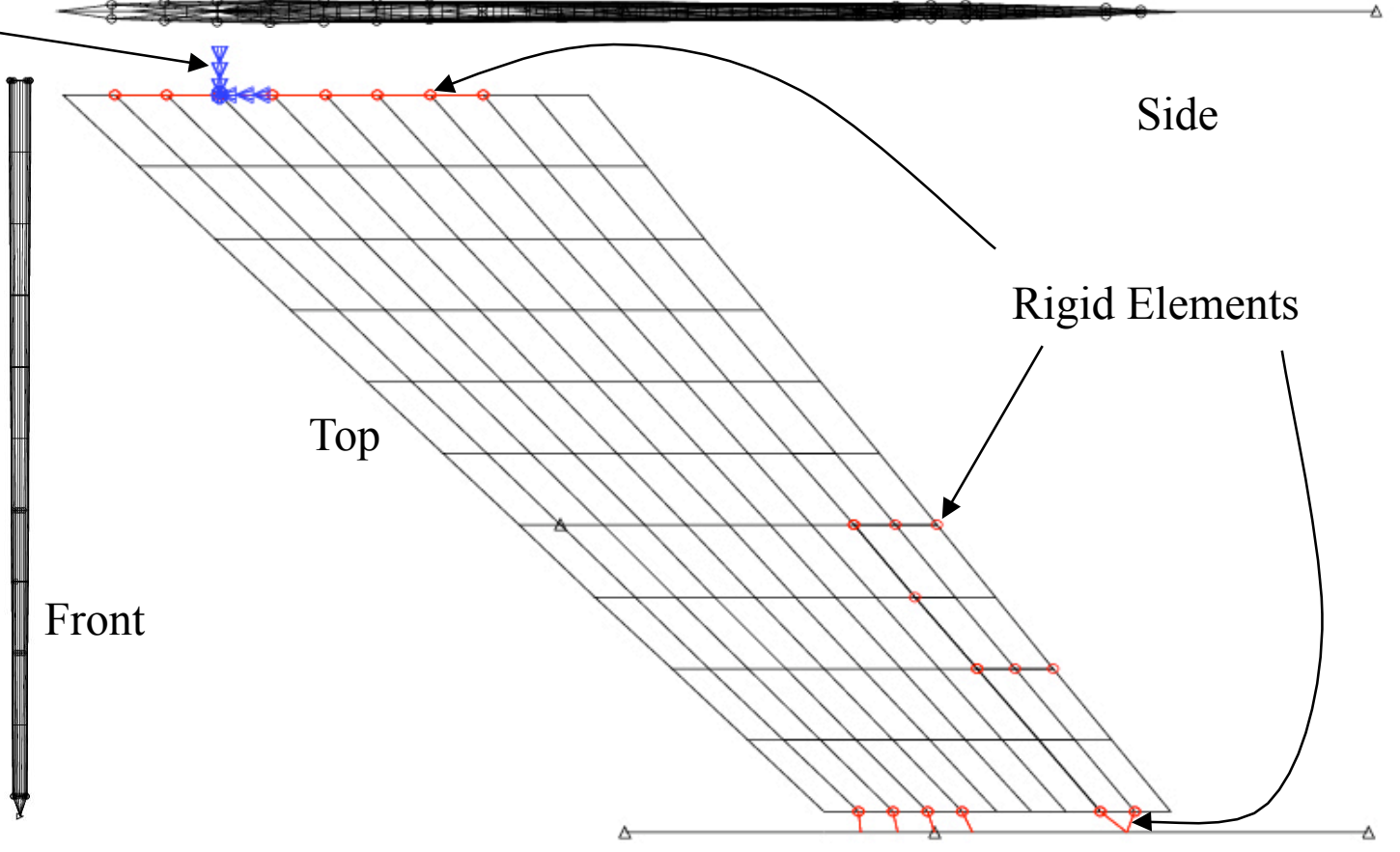




\section{Unsteady Aerodynamic Model}

口 Based on ZAERO code

* 416 elements

- Select 16 reduced frequencies between 0 \& 1

* Mach $=.60, .75, .82$, and .95

* Linear Theory

* Use Matched Flutter Analysis

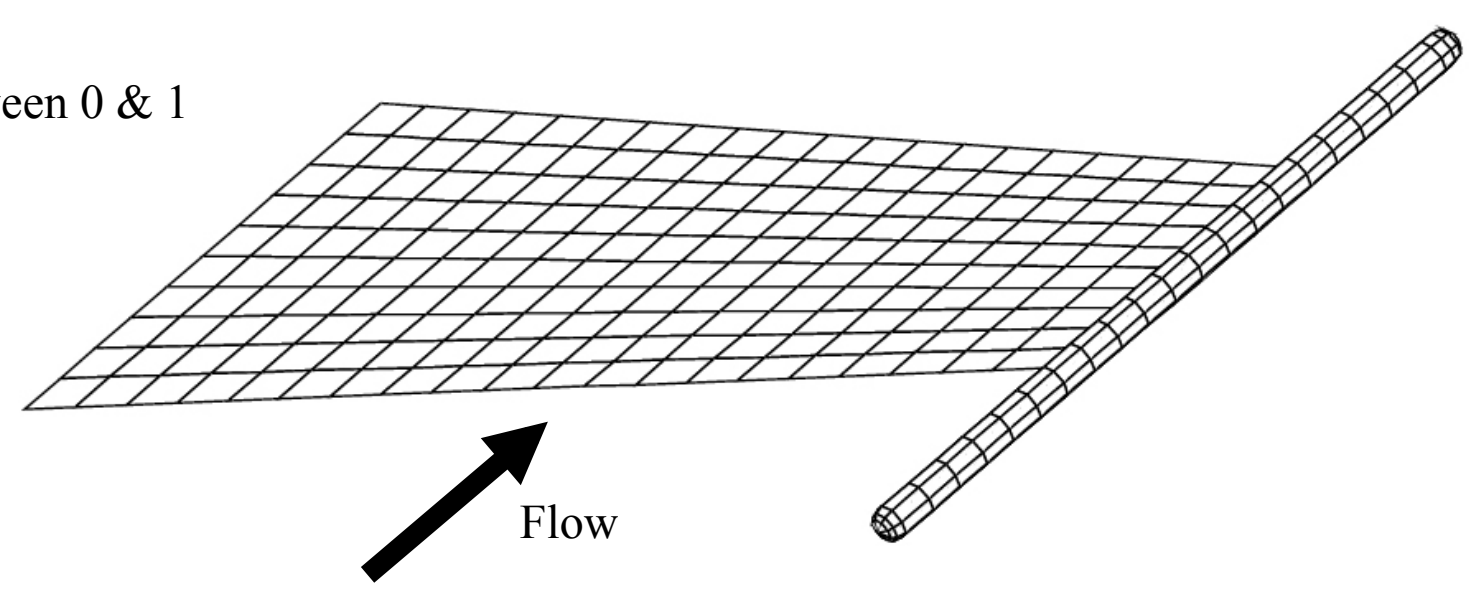

Splining Points
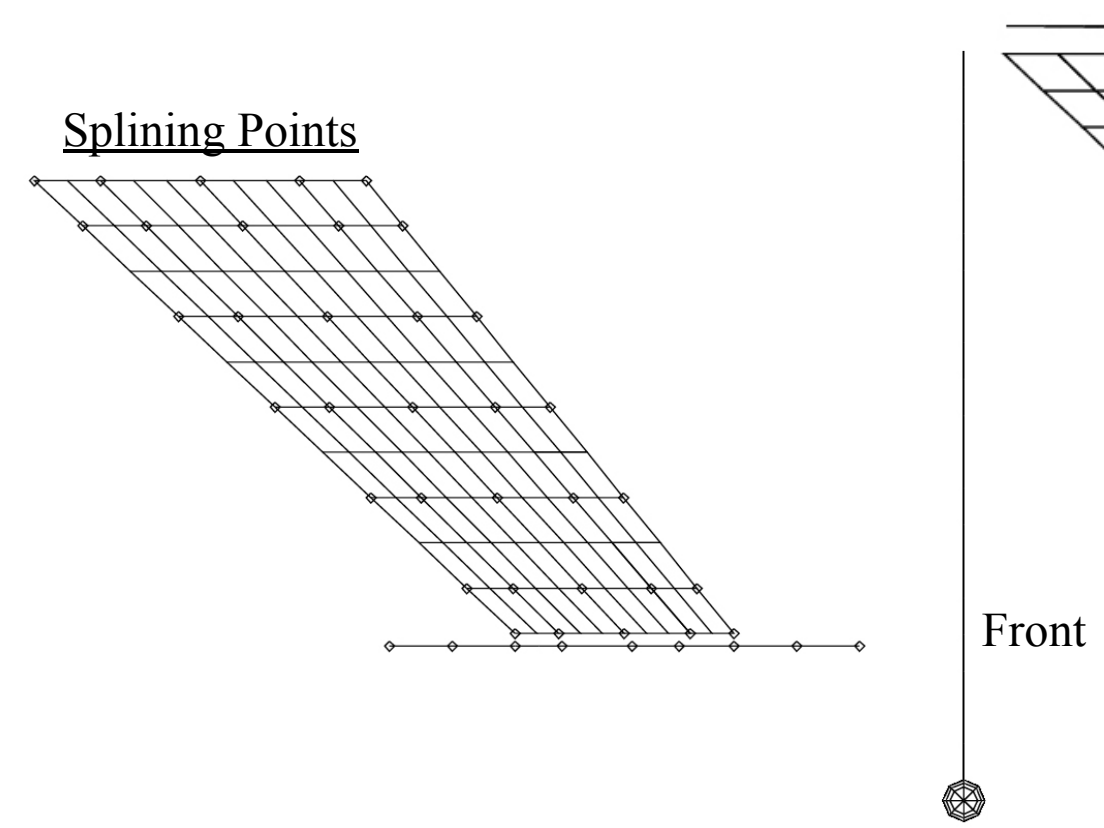

W111111

Side 


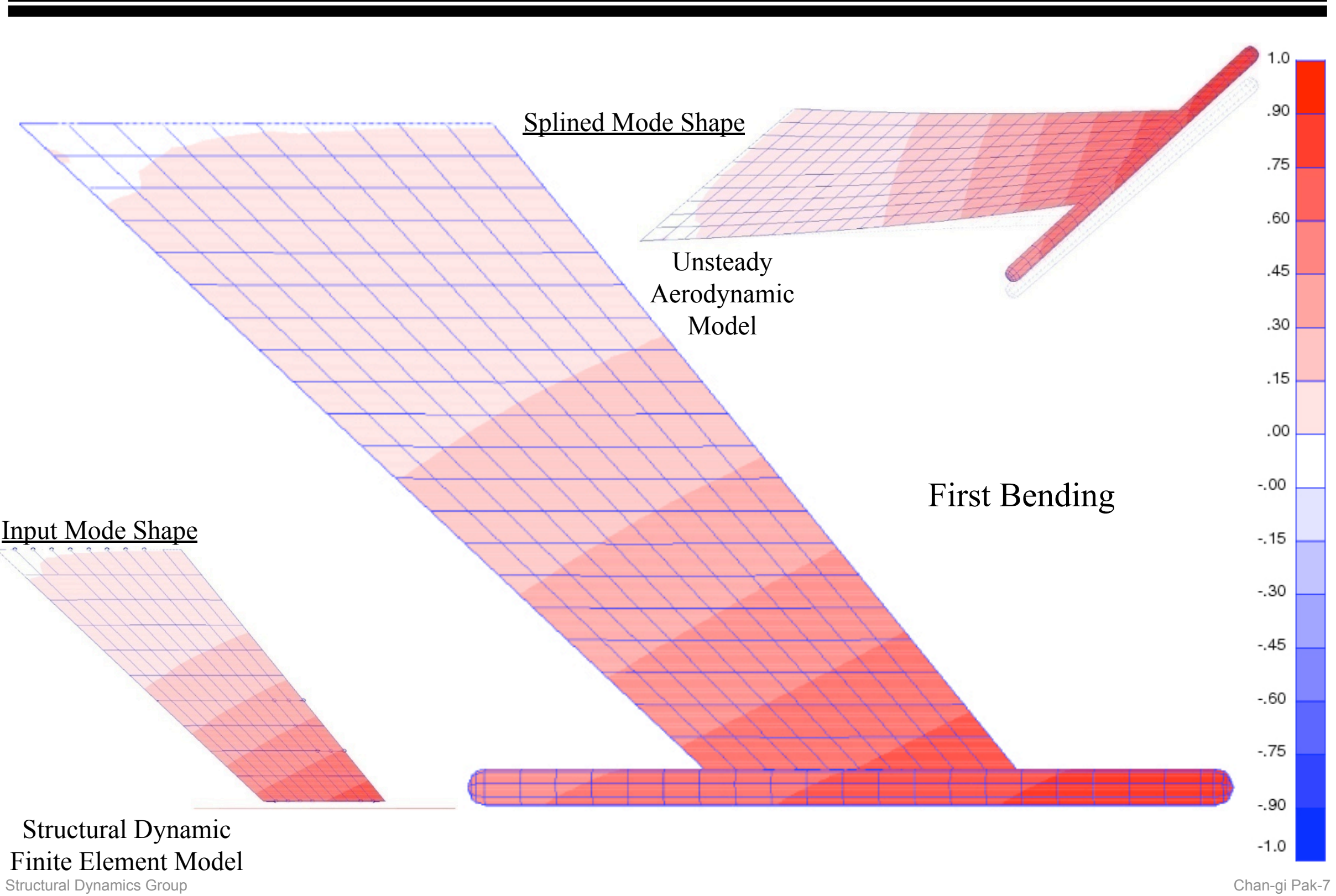


Nodal Line

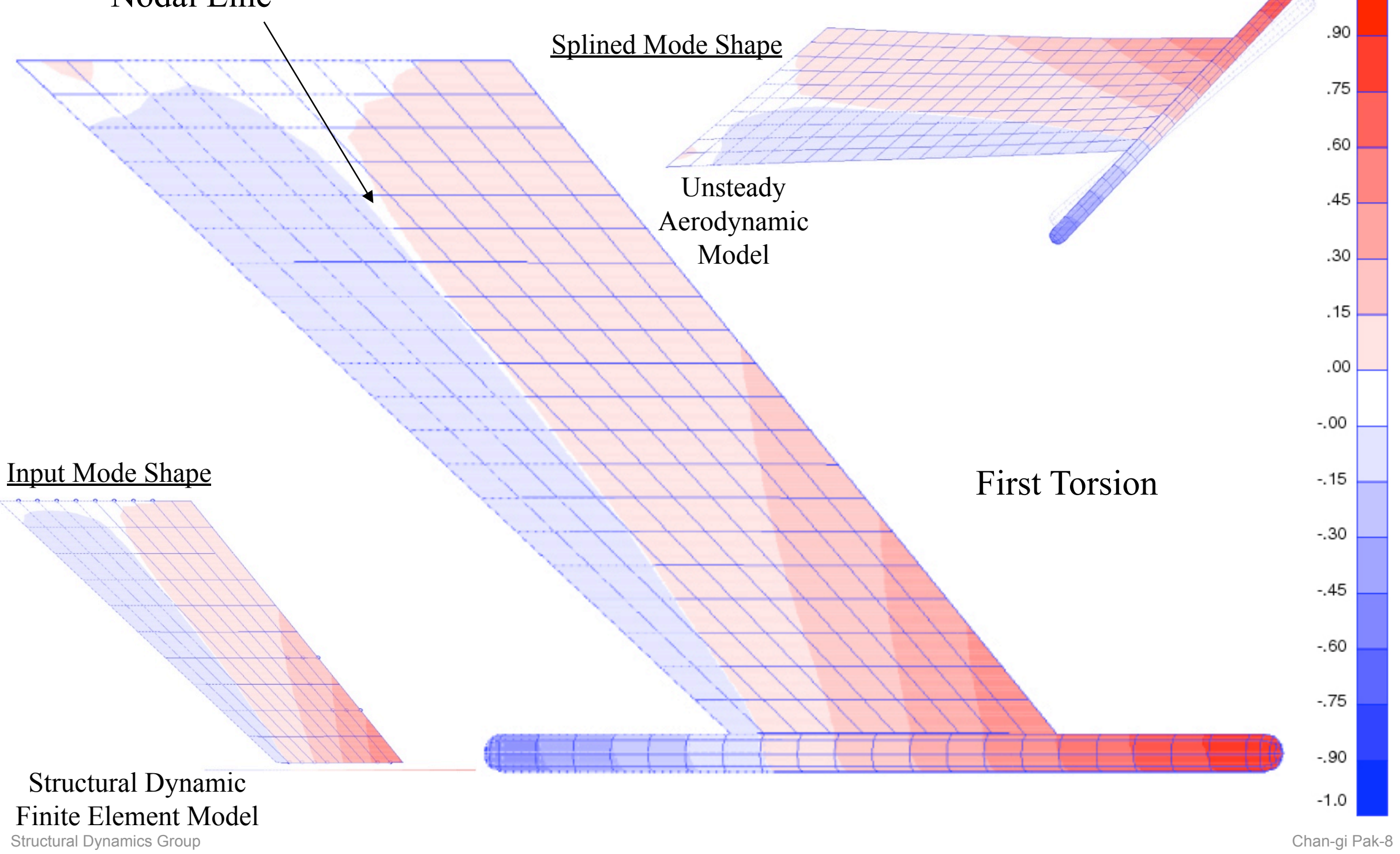




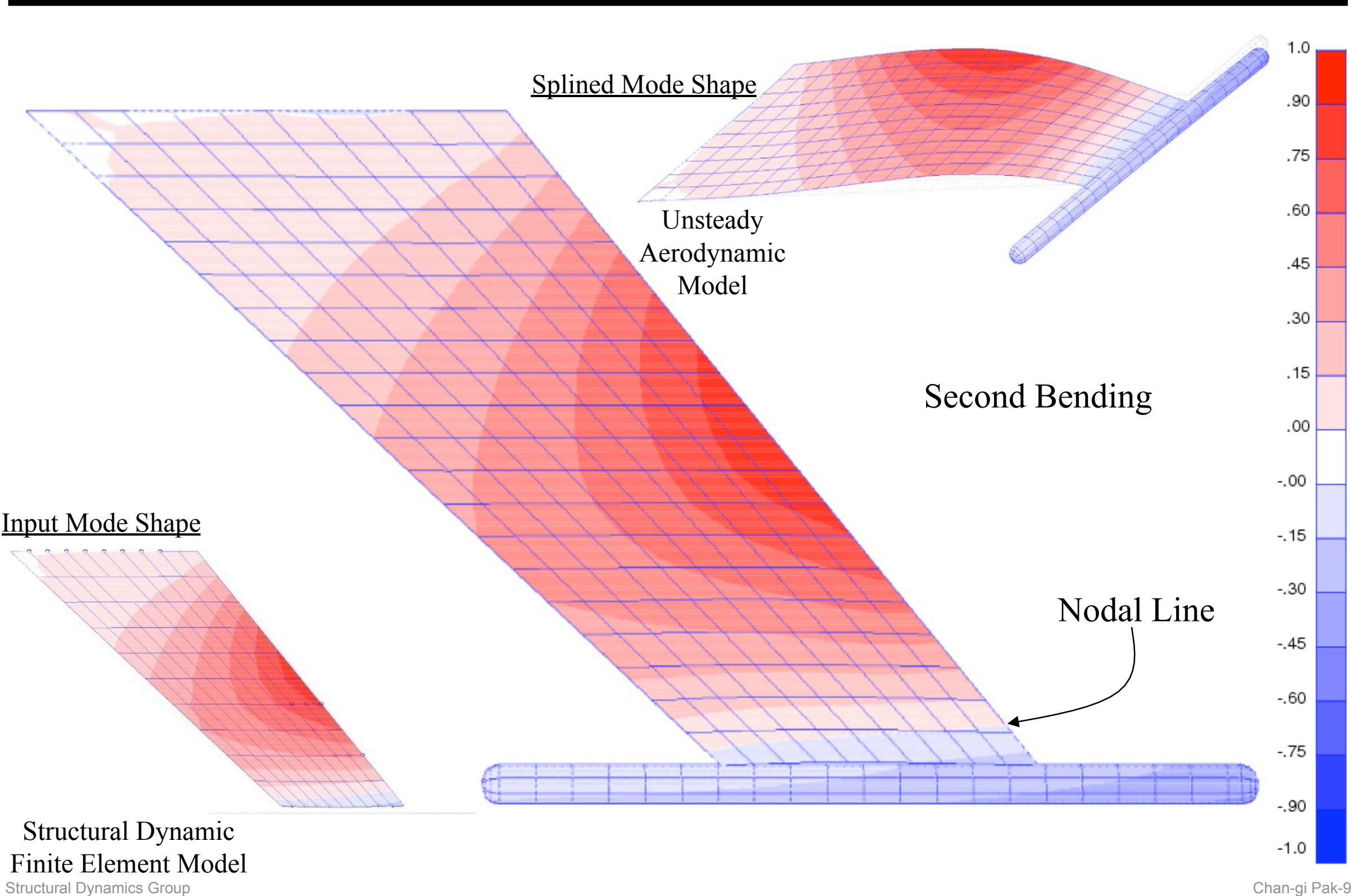




\section{Splined Aerodynamic Loads at Mach $=0.82$}

Input: Cp Distribution

Output: Splined Loads

Unsteady

Aerodynamic

Model
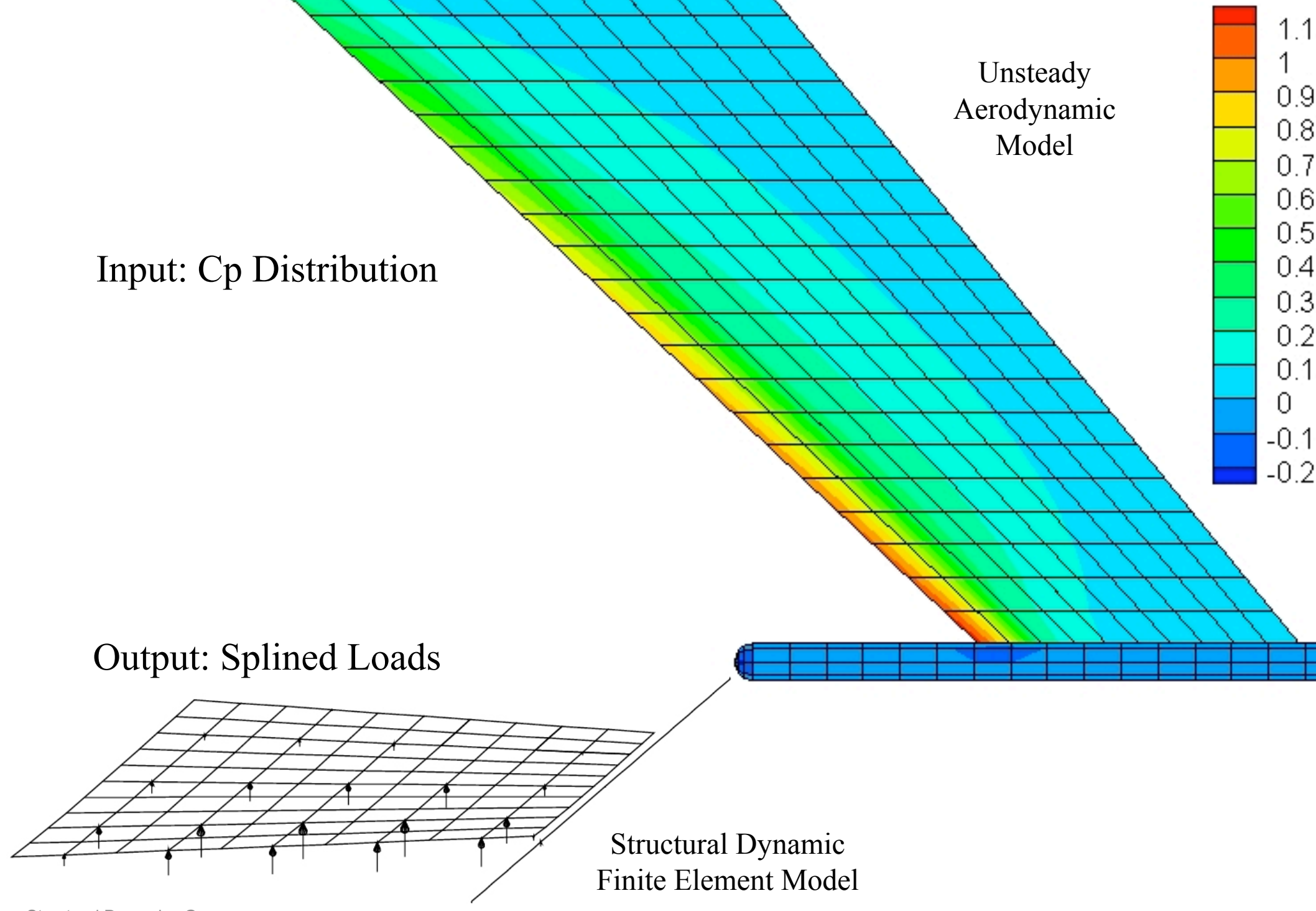

Finite Element Model 


\section{V-g and V-w Curves at Mach $=0.82$ Before Model Tuning}
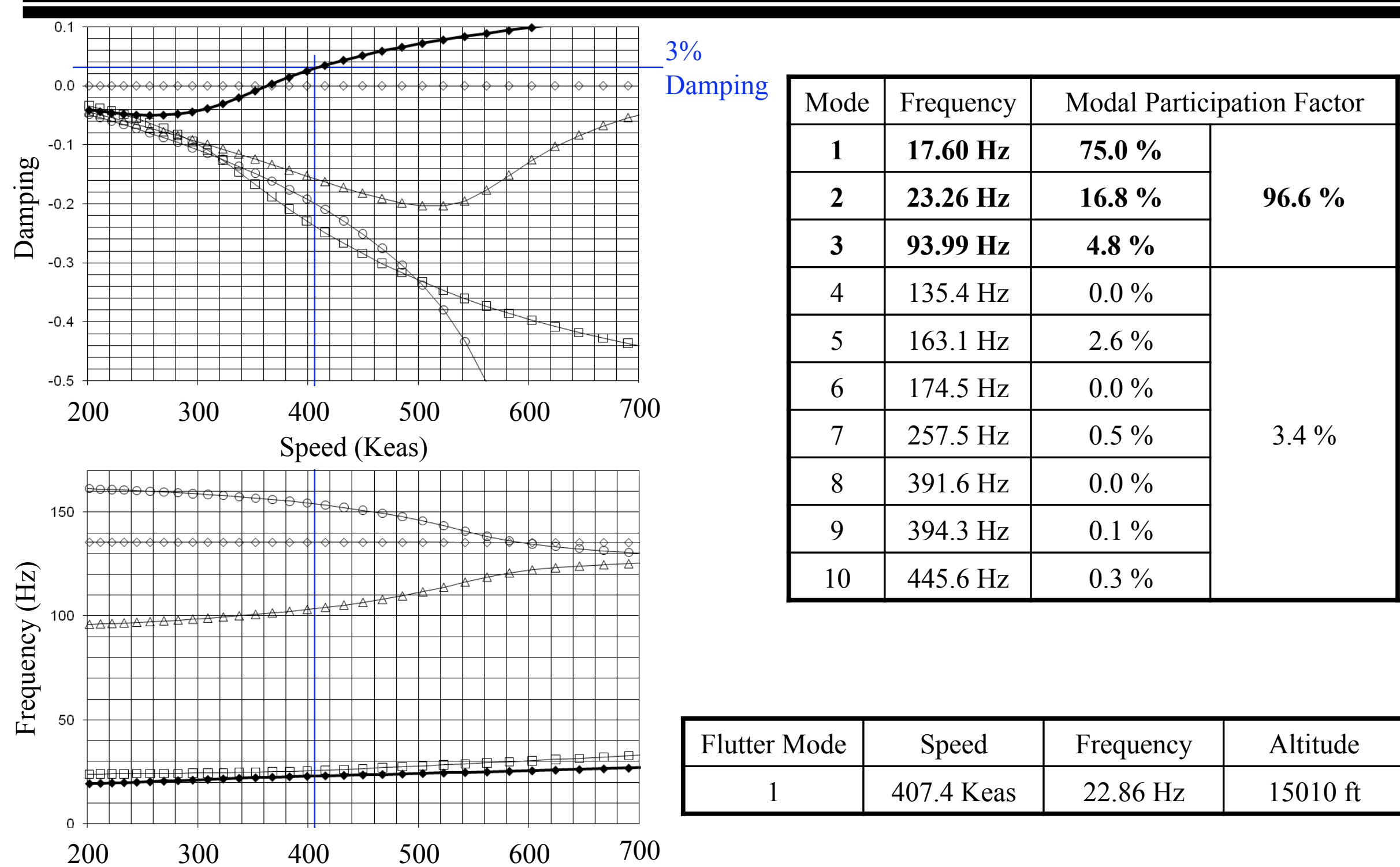

\begin{tabular}{|c|c|c|c|}
\hline Flutter Mode & Speed & Frequency & Altitude \\
\hline 1 & 407.4 Keas & $22.86 \mathrm{~Hz}$ & $15010 \mathrm{ft}$ \\
\hline
\end{tabular}

Speed (Keas) 


\section{Summary of the Modal Participation Factors}

\begin{tabular}{|c|c|c|c|c|c|c|c|c|c|}
\hline \multirow{3}{*}{$\begin{array}{c}\text { Mode } \\
1\end{array}$} & \multirow{3}{*}{$\begin{array}{c}\text { Frequency } \\
\mathbf{1 7 . 6 0 ~ H z}\end{array}$} & \multicolumn{8}{|c|}{ Modal Participation Factor } \\
\hline & & \multicolumn{2}{|c|}{ Mach $=0.60$} & \multicolumn{2}{|c|}{ Mach $=0.75$} & \multicolumn{2}{|c|}{$\operatorname{Mach}=0.82$} & \multicolumn{2}{|c|}{ Mach $=0.95$} \\
\hline & & $68.1 \%$ & \multirow{3}{*}{$95.5 \%$} & $72.9 \%$ & \multirow{3}{*}{$96.2 \%$} & $75.0 \%$ & \multirow{3}{*}{$96.6 \%$} & $79.7 \%$ & \multirow{3}{*}{$97.6 \%$} \\
\hline 2 & $23.26 \mathrm{~Hz}$ & $22.2 \%$ & & $18.3 \%$ & & $16.8 \%$ & & $13.6 \%$ & \\
\hline 3 & $93.99 \mathrm{~Hz}$ & $5.2 \%$ & & $5.0 \%$ & & $4.8 \%$ & & $4.3 \%$ & \\
\hline 4 & $135.4 \mathrm{~Hz}$ & $0.0 \%$ & \multirow{7}{*}{$4.5 \%$} & $0.0 \%$ & \multirow{7}{*}{$3.8 \%$} & $0.0 \%$ & \multirow{7}{*}{$3.4 \%$} & $0.0 \%$ & \multirow{7}{*}{$2.4 \%$} \\
\hline 5 & $163.1 \mathrm{~Hz}$ & $3.3 \%$ & & $2.9 \%$ & & $2.6 \%$ & & $1.9 \%$ & \\
\hline 6 & $174.5 \mathrm{~Hz}$ & $0.0 \%$ & & $0.0 \%$ & & $0.0 \%$ & & $0.0 \%$ & \\
\hline 7 & $257.5 \mathrm{~Hz}$ & $0.7 \%$ & & $0.6 \%$ & & $0.5 \%$ & & $0.3 \%$ & \\
\hline 8 & $391.6 \mathrm{~Hz}$ & $0.0 \%$ & & $0.0 \%$ & & $0.0 \%$ & & $0.0 \%$ & \\
\hline 9 & $394.3 \mathrm{~Hz}$ & $0.1 \%$ & & $0.1 \%$ & & $0.1 \%$ & & $0.0 \%$ & \\
\hline 10 & $445.6 \mathrm{~Hz}$ & $0.4 \%$ & & $0.3 \%$ & & $0.3 \%$ & & $0.2 \%$ & \\
\hline
\end{tabular}

- Participation of the first three modes is a function of Mach number.

In-plane modes do not participate for the first flutter mechanism at all.

* Modes 4, 6, and 8

- Primary Modes: Modes 1, 2, and 3

* Frequency error should be less than 3\%.

Secondary Modes: Modes 4 through 10 (higher)

* Frequency error should be less than $10 \%$. 


\section{Model Correlation Requirements}

Everyone believes the test data except for the experimentalist, and no one believes the finite element model except for the analyst.

* Some of the discrepancies come from analytical Finite Element modeling uncertainties, noise in the test results, and/or inadequate sensor and actuator locations. Not the same orientation for each sensor.

口 MIL-STD-1540C Section 6.2.10

* Test Requirements for Launch, Upper-Stage, \& Space Vehicles

* Less than $\underline{3 \%}$ and $10 \%$ frequency errors for the primary and secondary modes, respectively

- Less than $\underline{10 \%}$ off-diagonal terms in orthonormalized mass matrix

a AFFTC-TIH-90-001 (Structures Flight Test Handbook)

* If measured mode shapes are going to be associated with a finite element model of the structure, it will probably need to be adjusted to match the lumped mass modeling of the analysis.

* Based on the measured mode shape matrix F and the analytical mass matrix M, the following operation is performed:

\section{$\Phi^{\top} \mathrm{M} \Phi$}

* The results is near diagonalization of the resulting matrix with values close to 1 on the diagonal and values close to zero in the off-diagonal terms. Experimental reality dictates that the data will not produce exact unity or null values, so 10 percent of these targets are accepted as good orthogonality and the data can be confidently correlated with the finite element model. 


\section{Sensor/Actuator Placement Methods}

$\square$ Given Number of Sensors and Number of Modes

$\square$ Find the best sensor locations

* Effective Independence Method

$>$ Step 1: Compute $\boldsymbol{E}=\overline{\boldsymbol{\Phi}}\left(\Phi^{T} \overline{\boldsymbol{\Phi}}\right)^{-1} \overline{\boldsymbol{\Phi}}^{T}$

$>$ Step 2: Remove DOF with the smallest value

$>$ Step 3: Repeat $1 \& 2$ until number of DOFs equal to number of sensors

* Genetic Algorithm

> Maximize: objective function $=$ determinant of FIM

$>$ Design variables: Sensor location

* Kinetic Energy Sorting

* Guyan Reduction

* Iterative Guyan Reduction

* Driving Point Residues

Find the approach gives "maximum determinant value" of Fisher Information Matrix * FIM $\equiv \bar{\Phi}^{T} \bar{\Phi}$ 


\section{Model Tuning Procedure}

a Optimization Problem Statement

* Minimize $J_{i}$

* Such that $\left|J_{k}\right| \leq \varepsilon_{k} \quad k=1 \ldots 13 \quad \& \quad k \neq i$

$\square \quad$ Step 1: Improve Rigid Body Mass Properties

- Errors in Total Mass

* Errors in CG Locations

* Errors in Mass Moment of Inertias

Infeasible

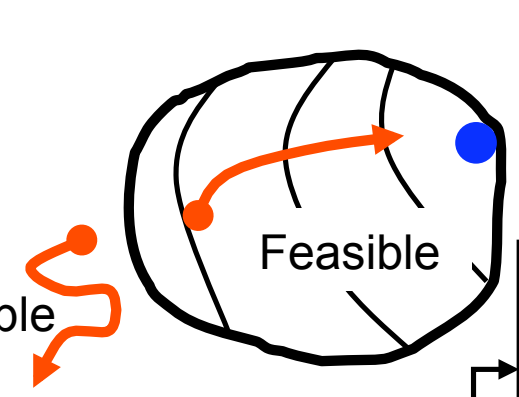

$\longrightarrow$

\begin{tabular}{|c|c|c|}
\hline Mass Properties & Objective Functions \& Cons & aints \\
\hline Total Mass & $J_{1}=\left(\mathrm{W}-\mathrm{W}_{\mathrm{G}}\right)^{2} / \mathrm{W}_{\mathrm{G}}^{2}$ & \\
\hline \multirow{3}{*}{ CG Locations } & $J_{2}=\left(\mathrm{X}-\mathrm{X}_{\mathrm{G}}\right)^{2} / \mathrm{X}_{\mathrm{G}}^{2}$ & \multirow{3}{*}{$\begin{array}{l}\text { Measure Weight, C.G., } \\
\text { \& Moment of inertia } \\
\text { GVT } \\
\quad F_{G}, w_{G}\end{array}$} \\
\hline & $J_{3}=\left(\mathrm{Y}-\mathrm{Y}_{\mathrm{G}}\right)^{2} / \mathrm{Y}_{\mathrm{G}}^{2}$ & \\
\hline & $J_{4}=\left(Z-Z_{G}\right)^{2} / Z_{G}^{2}$ & \\
\hline \multirow{6}{*}{ Mass Moment of Inertias } & $J_{5}=\left(\mathrm{I}_{\mathrm{XX}}-\mathrm{I}_{\mathrm{XXG}}\right)^{2} / \mathrm{I}_{\mathrm{XXG}}{ }^{2}$ & \\
\hline & $J_{6}=\left(\mathrm{I}_{\mathrm{YY}}-\mathrm{I}_{\mathrm{YYG}}\right)^{2} / \mathrm{I}_{\mathrm{YYG}}{ }^{2}$ & \\
\hline & $J_{7}=\left(\mathrm{I}_{\mathrm{ZZ}}-\mathrm{I}_{\mathrm{ZZG}}\right)^{2} / \mathrm{I}_{\mathrm{ZZG}}{ }^{2}$ & \\
\hline & $J_{8}=\left(\mathrm{I}_{\mathrm{XY}}-\mathrm{I}_{\mathrm{XYG}}\right)^{2} / \mathrm{I}_{\mathrm{XYG}}{ }^{2}$ & \\
\hline & $J_{9}=\left(\mathrm{I}_{\mathrm{YZ}}-\mathrm{I}_{\mathrm{YZG}}\right)^{2} / \mathrm{I}_{\mathrm{YZG}}{ }^{2}$ & \\
\hline & $J_{10}=\left(\mathrm{I}_{\mathrm{ZX}}-\mathrm{I}_{\mathrm{ZXG}}\right)^{2} / \mathrm{I}_{\mathrm{ZXG}}{ }^{2}$ & \\
\hline
\end{tabular}

Optimization Step 2: Improve Orthogonality of Mass Matrix $\underline{M}$

$\downarrow$

Optimization Step 3:

Update Frequencies $\&$ Mode Shapes

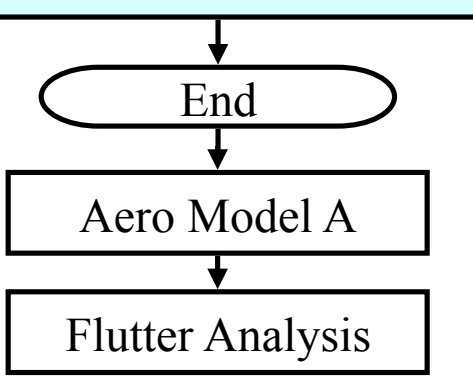




\section{Model Tuning Procedure (continued)}

- Step 2: Improve Mass Matrix

* Off-diagonal terms of Orthonormalized Mass Matrix: $\underline{\mathbf{M}}=\mathbf{F}_{\mathrm{G}}{ }^{\mathrm{T}} \mathbf{T}^{\mathrm{T}} \mathbf{M} \mathbf{T F}_{\mathrm{G}}$ Guyan reduction

$$
\begin{aligned}
& T=T_{G}=\left[\begin{array}{c}
I \\
-K_{s s}^{-1} K_{s m}
\end{array}\right] \quad M=\left[\begin{array}{c}
M_{m m} M_{m s} \\
M_{s m} M_{s s}
\end{array}\right] \quad K=\left[\begin{array}{c}
K_{m m} K_{m s} \\
K_{s m} K_{s s}
\end{array}\right] \\
& M_{G}=T_{G}^{T} M T_{G} \quad K_{G}=T_{G}^{T} K T_{G}
\end{aligned}
$$

Improved reduction system

$T=T_{I R S}=\left[\begin{array}{c}I \\ -K_{s s}^{-1} K_{s m}+\left(K_{s s}^{-1} M_{s s}-K_{s s}^{-1} M_{s s} K_{s s}^{-1} K_{s m}\right) M_{G}^{-1} K_{G}\end{array}\right]$

System Equivalent Reduction Expansion Process (SEREP)

$T=T_{\text {SEREP }}=\left[\begin{array}{l}\boldsymbol{\Phi}_{m}\left(\boldsymbol{\Phi}_{m}^{T} \boldsymbol{\Phi}_{m}\right)^{-1} \boldsymbol{\Phi}_{m}^{T} \\ \boldsymbol{\Phi}_{s}\left(\boldsymbol{\Phi}_{m}^{T} \boldsymbol{\Phi}_{m}\right)^{-1} \boldsymbol{\Phi}_{m}^{T}\end{array}\right]$

$$
\Phi=\left[\begin{array}{l}
\Phi_{m} \\
\Phi_{s}
\end{array}\right]
$$

$$
J_{11}=\sum_{i=1, j=1, i \neq j}^{n} \frac{M_{i j}^{2}}{2}
$$

Measure Weight, C.G., \& Moment of inertia GVT

$$
\mathrm{F}_{\mathrm{G}}, \mathrm{w}_{\mathrm{G}}
$$

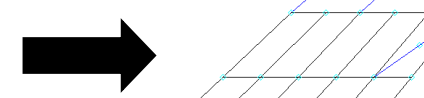

GVT
Optimization Step 1: Update Mass Properties $\mathrm{W}, \mathrm{X}_{\mathrm{CG}}, \mathrm{Y}_{\mathrm{CG}}, \mathrm{Z}_{\mathrm{CG}}, \mathrm{Ixx}$, Iyy, Izz, Ixy, Iyz, \& Izx

Optimization Step 2: Improve Orthogonality of Mass Matrix $\underline{\mathrm{M}}$

$\downarrow$

Optimization Step 3:

Update Frequencies \& Mode Shapes

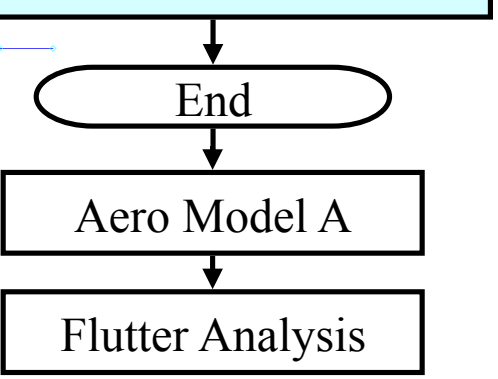




\section{Model Tuning Procedure (continued)}

Step 3: Frequencies and Mode Shapes

* Errors in Frequencies

$$
J_{12}=\sum_{i=1}^{n}\left(\frac{\Omega_{i}-\omega_{i}}{\Omega_{i}}\right)^{2}
$$

* Option 1: Off-diagonal terms of Orthonormalized Stiffness Matrix:

$$
\underline{\mathbf{K}}=\mathbf{F}_{\mathrm{G}}{ }^{\mathrm{T}} \mathbf{T}^{\mathrm{T}} \mathbf{K} \mathbf{T F}_{\mathrm{G}}
$$

$$
J_{13}=\sum_{i=1, j=1, i \neq j}^{n} \underline{K}_{i j}^{2}
$$

Measure Weight, C.G.,
\& Moment of inertia
GVT $\mathrm{F}_{\mathrm{G}}, \mathrm{w}_{\mathrm{G}}$

* Option 2: Errors in Mode Shapes

$$
J_{13}=\sum_{i=1}^{m}\left(\Phi_{i}-\Phi_{i G}\right)^{2}
$$

$\mathrm{n}$ : number of modes $\mathrm{m}$ : number of sensors

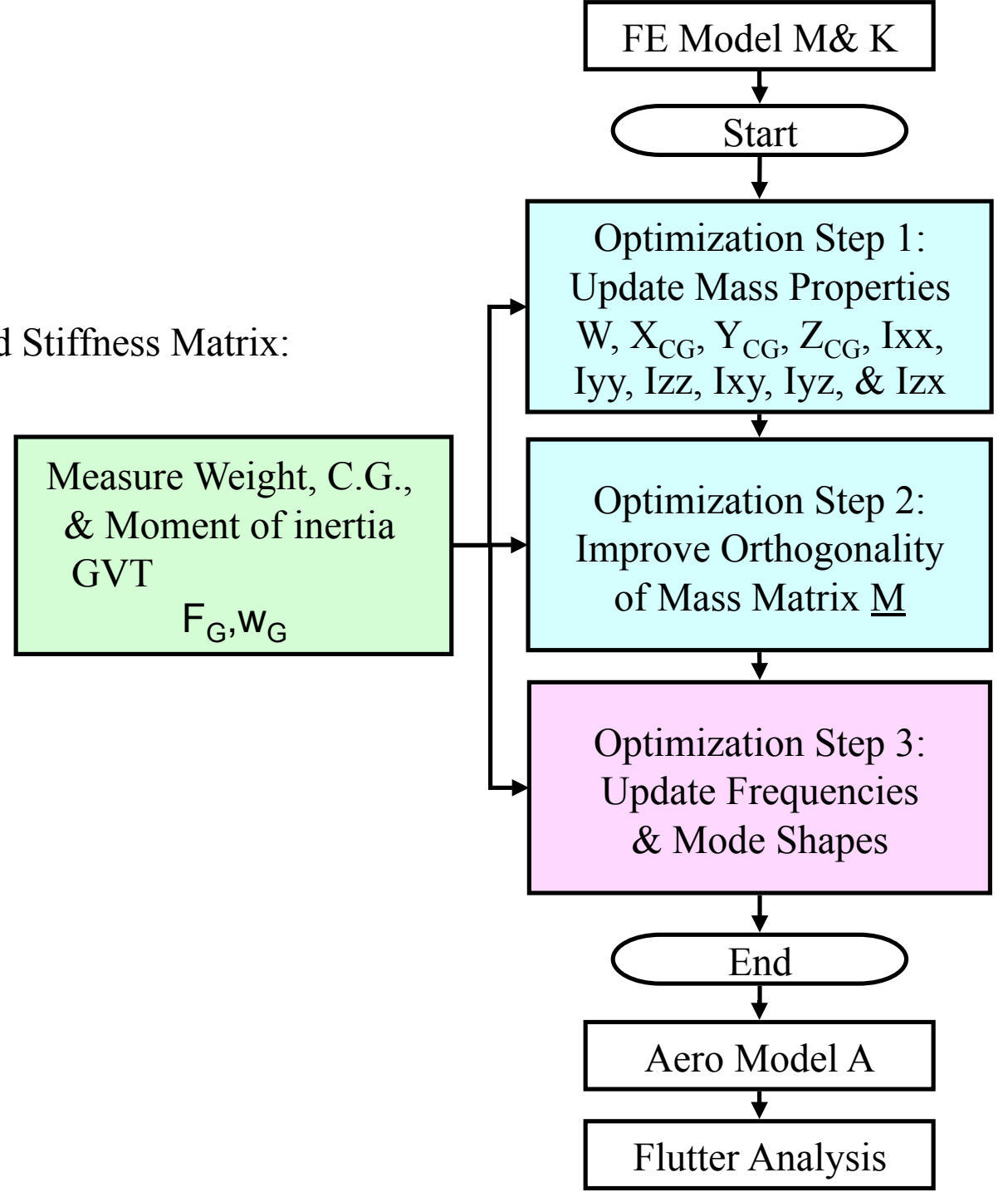




\section{Test Setup}



\section{Results (Frequency Comparisons)}

\begin{tabular}{|c|c|c|c|c|c|c|c|}
\hline \multirow[b]{2}{*}{ Mode } & \multirow[b]{2}{*}{ GVT } & \multicolumn{2}{|c|}{ Before Tuning } & \multicolumn{2}{|c|}{ After Tuning } & \multirow{2}{*}{$\begin{array}{c}\text { MIL-STD } \\
\text { Requirements } \\
(\%)\end{array}$} & \multirow[b]{2}{*}{ Comments } \\
\hline & & $\begin{array}{l}\text { NASTRAN } \\
\text { (Guyan/Full) }\end{array}$ & $\begin{array}{l}\% \\
\text { Error }\end{array}$ & $\begin{array}{c}\text { NASTRAN } \\
\text { (SEREP/Full) }\end{array}$ & $\begin{array}{l}\% \\
\text { Error }\end{array}$ & & \\
\hline 1 & 17.24 & $17.61 / 17.60$ & $2.1 / 2.1$ & $17.79 / 17.79$ & $3.2 / 3.2$ & 3 & First Bending \\
\hline 2 & 44.10 & $23.27 / 23.26$ & $-47 /-47$ & 44.71/44.71 & 1.4/1.4 & 3 & First Torsion \\
\hline 3 & 84.00 & $99.02 / 93.99$ & $18 / 6.3$ & $84.33 / 84.33$ & $.39 / .39$ & 3 & Second Bending \\
\hline 4 & N/A & .../135.4 & N/A & .../132.4 & N/A & 10 & First In-Plane Wing Bending \\
\hline 5 & $\mathrm{~N} / \mathrm{A}$ & $\ldots / 163.1$ & N/A & $\ldots / 129.3$ & N/A & 10 & Second Bending + First Torsion \\
\hline
\end{tabular}

Mode 1

Mode 2

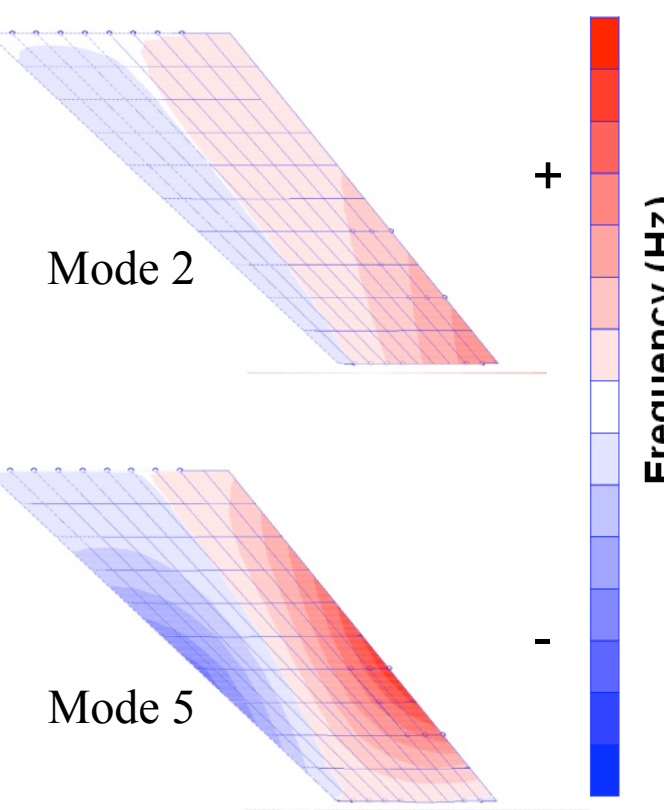

Mode 5

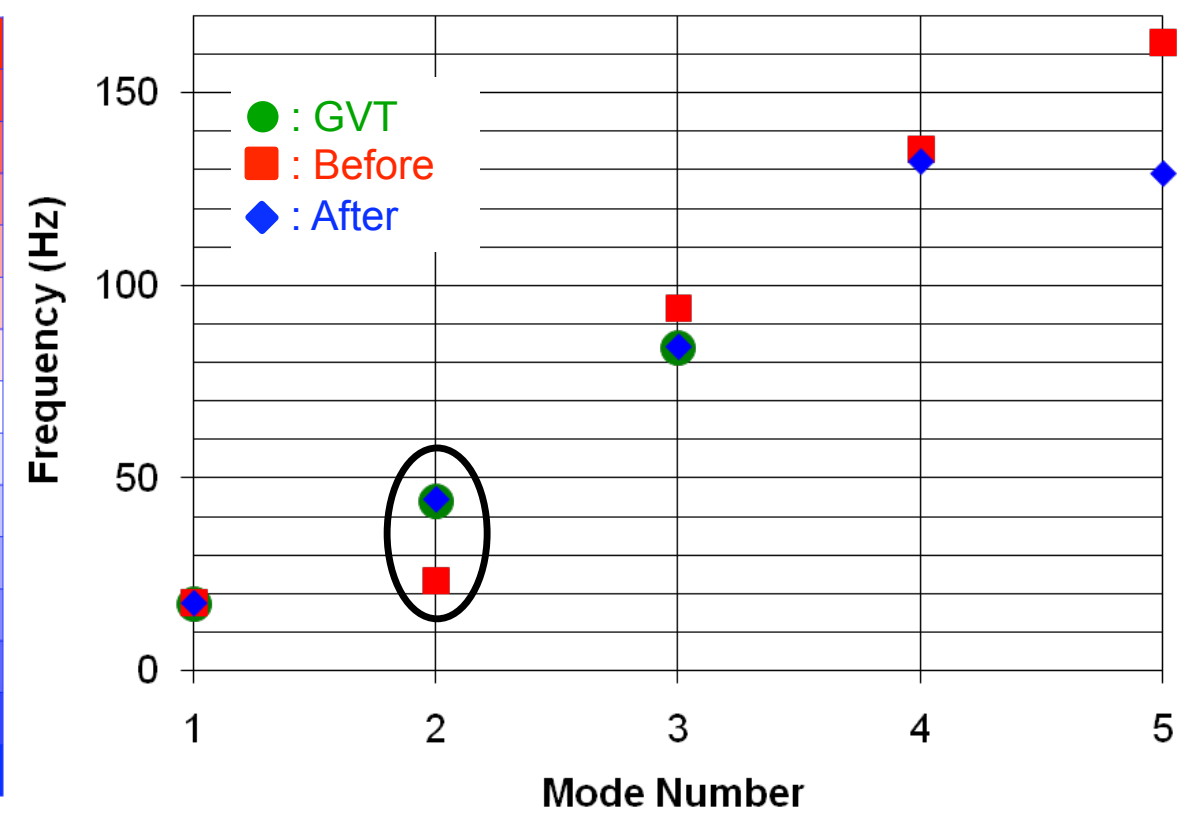




\section{Results (Total Weight, Orthogonality, \& MAC)}

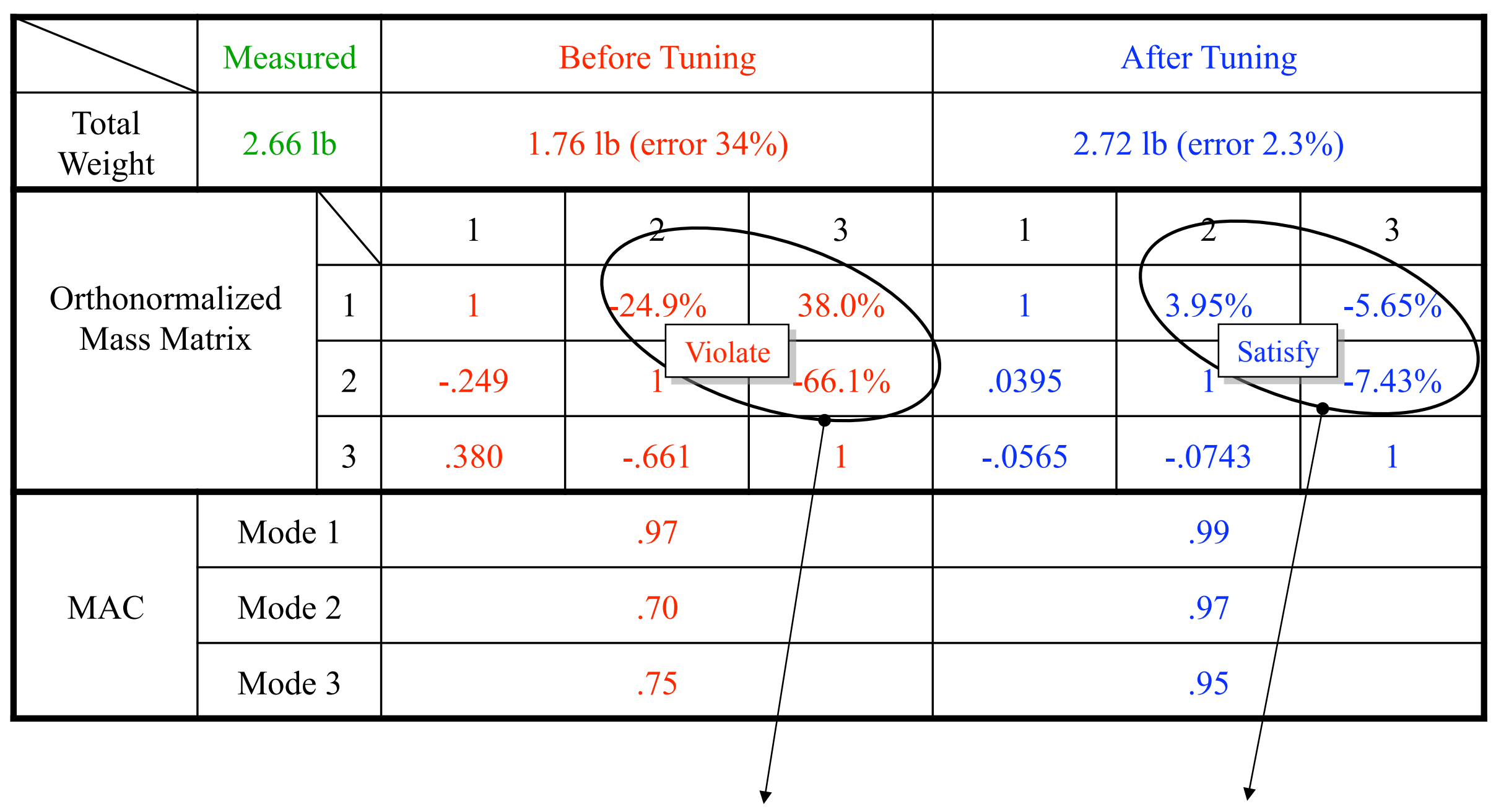

MIL-STD \& AFFTC-TIH-90-001 Requirements: 10\% 


\section{V-g and V-w Curves at Mach $=0.82$ After Model Tuning}

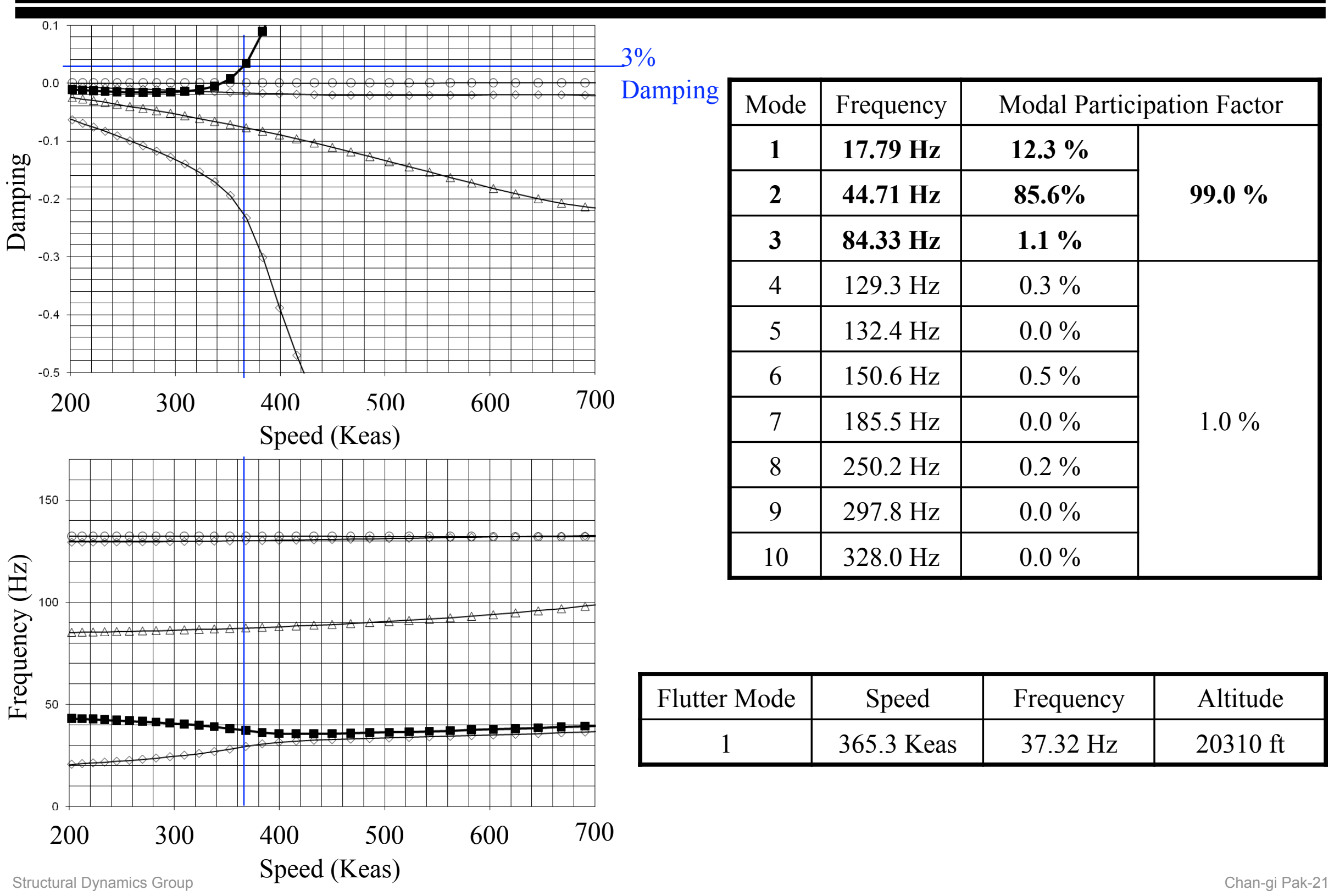




\section{Flutter Results Before \& After Model Tuning}

\begin{tabular}{|c|c|c|c|c|c|c|c|c|c|}
\hline \multirow{3}{*}{$\begin{array}{c}\text { Mode } \\
1 \\
\end{array}$} & \multirow{3}{*}{$\begin{array}{c}\text { Frequency } \\
17.60 \mathrm{~Hz} \\
\end{array}$} & \multicolumn{8}{|c|}{ Modal Participation Factors before Model Tuning } \\
\hline & & \multicolumn{2}{|c|}{$\operatorname{Mach}=0.60$} & \multicolumn{2}{|c|}{$\operatorname{Mach}=0.75$} & \multicolumn{2}{|c|}{ Mach $=0.82$} & \multicolumn{2}{|c|}{ Mach $=0.95$} \\
\hline & & $68.1 \%$ & \multirow{3}{*}{$95.5 \%$} & $72.9 \%$ & \multirow{3}{*}{$96.2 \%$} & $75.0 \%$ & \multirow{3}{*}{$96.6 \%$} & $79.7 \%$ & \multirow{3}{*}{$97.6 \%$} \\
\hline 2 & $23.26 \mathrm{~Hz}$ & $22.2 \%$ & & $18.3 \%$ & & $16.8 \%$ & & $13.6 \%$ & \\
\hline 3 & $93.99 \mathrm{~Hz}$ & $5.2 \%$ & & $5.0 \%$ & & $4.8 \%$ & & $4.3 \%$ & \\
\hline \multirow{2}{*}{ Mode } & \multirow{2}{*}{ Frequency } & \multicolumn{8}{|c|}{ Modal Participation Factors after Model Tuning } \\
\hline & & \multicolumn{2}{|c|}{ Mach $=0.60$} & \multicolumn{2}{|c|}{ Mach $=0.75$} & \multicolumn{2}{|c|}{ Mach $=0.82$} & \multicolumn{2}{|c|}{ Mach $=0.95$} \\
\hline 1 & $17.79 \mathrm{~Hz}$ & $6.7 \%$ & \multirow{3}{*}{$99.2 \%$} & $9.8 \%$ & \multirow{3}{*}{$99.1 \%$} & $12.3 \%$ & \multirow{3}{*}{$99.0 \%$} & $24.3 \%$ & \multirow{3}{*}{$98.3 \%$} \\
\hline 2 & $44.71 \mathrm{~Hz}$ & $91.9 \%$ & & $88.4 \%$ & & $85.6 \%$ & & $72.4 \%$ & \\
\hline 3 & $84.33 \mathrm{~Hz}$ & $0.6 \%$ & & $0.9 \%$ & & $1.1 \%$ & & $1.6 \%$ & \\
\hline
\end{tabular}

\begin{tabular}{|c|c|c|c|c|c|}
\hline \multicolumn{2}{|c|}{\begin{tabular}{|c|c|c|c|c|} 
Before \\
Tuning
\end{tabular}} & Mach $=0.60$ & Mach $=0.75$ & Mach $=0.82$ & Mach $=0.95$ \\
\cline { 2 - 7 } & Frequency & $23.18 \mathrm{~Hz}$ & $22.97 \mathrm{~Hz}$ & $22.86 \mathrm{~Hz}$ & $22.53 \mathrm{~Hz}$ \\
\cline { 2 - 7 } & Altitude & $-7501 \mathrm{ft}$ & $8751 \mathrm{ft}$ & $15010 \mathrm{ft}$ & $25590 \mathrm{ft}$ \\
\hline \multirow{3}{*}{$\begin{array}{c}\text { After } \\
\text { Tuning }\end{array}$} & Speed & $361.3 \mathrm{Keas}$ & $364.6 \mathrm{Keas}$ & $365.3 \mathrm{Keas}$ & $367.0 \mathrm{Keas}$ \\
\cline { 2 - 7 } & Frequency & $38.47 \mathrm{~Hz}$ & $37.73 \mathrm{~Hz}$ & $37.32 \mathrm{~Hz}$ & $36.20 \mathrm{~Hz}$ \\
\cline { 2 - 7 } & Altitude & $5101 \mathrm{ft}$ & $16080 \mathrm{ft}$ & $20310 \mathrm{ft}$ & $26920 \mathrm{ft}$ \\
\hline \multicolumn{2}{|c|}{ Speed Error } & $\mathbf{2 5 . 4} \mathbf{\%}$ & $\mathbf{1 5 . 6} \%$ & $\mathbf{1 1 . 5 \%}$ & $\mathbf{3 . 0} \%$ \\
\hline
\end{tabular}




\section{Flutter Boundary vs. Flight Envelope}

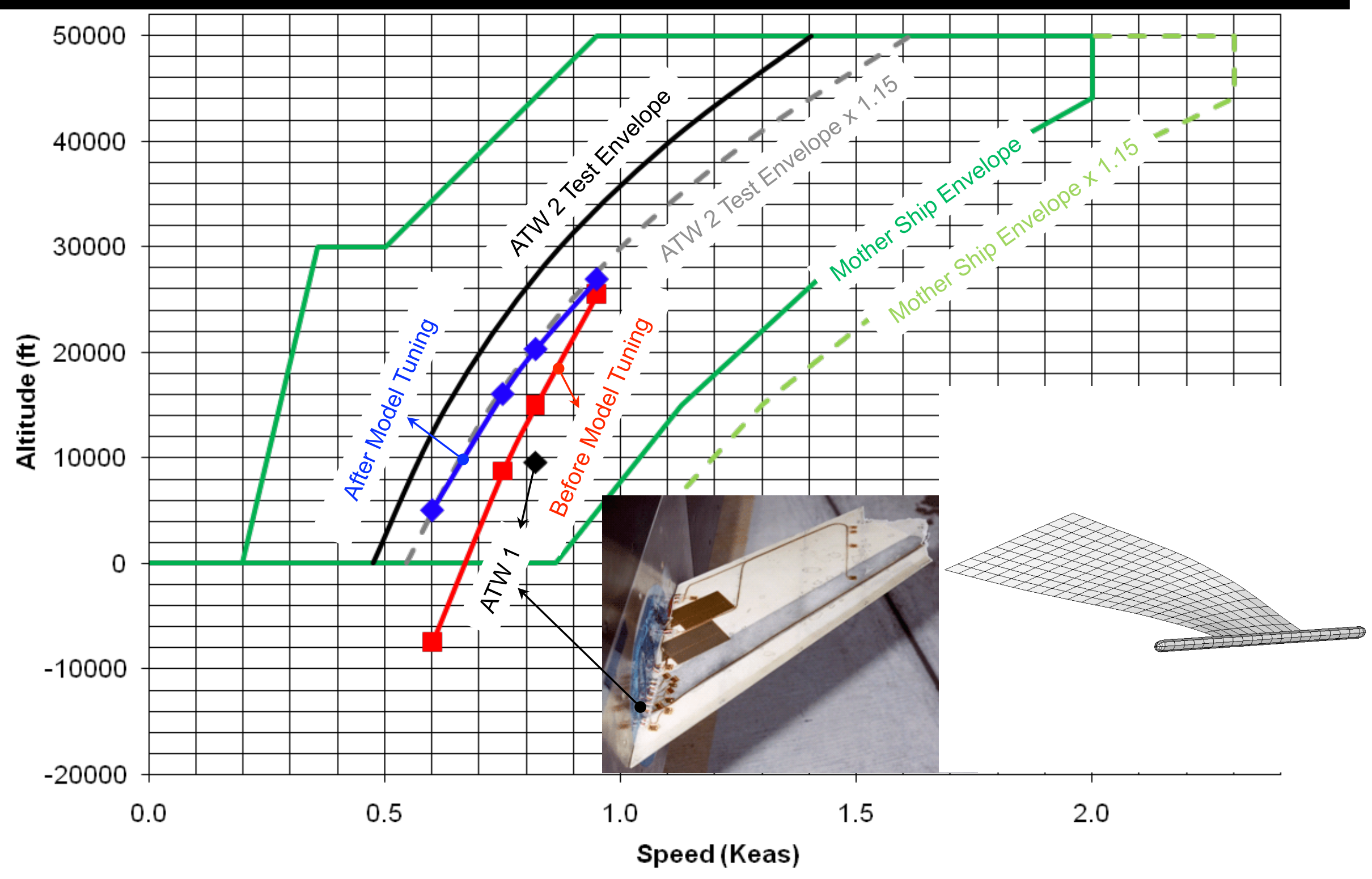




\section{Conclusion}

Model tuning based on GVT data is needed to minimize uncertainties in the structural dynamic model and to increase the safety of flight.

$\square$ After model tuning (for ATW 2 case)

* Maximum of $47 \%$ primary frequency error in second mode becomes $1.4 \%$.

$>$ Should be less than $3 \%$

* Maximum of $66 \%$ error in off-diagonal terms of orthonormalized mass matrix becomes $7.4 \%$.

$>$ Should be less than $10 \%$

* Maximum error in flutter speed is $25 \%$ (Mach $=0.60$ )

$>$ Modal participation of the second mode vs. Flutter speed error

$\begin{array}{lll}\checkmark \text { Mach }=0.60: & 91.9 \% & 25.4 \% \\ \checkmark \text { Mach }=0.75: & 88.4 \% & 15.6 \% \\ \checkmark \text { Mach }=0.82: & 85.6 \% & 11.5 \% \\ \checkmark \text { Mach }=0.95: & 72.4 \% & 3.0 \%\end{array}$

$>$ Without model tuning $40 \%$ of flutter margin is needed.

$\checkmark 15 \%$ MIL-SPEC requirement $+25 \%$ modeling uncertainty

* Modal participation of the first three modes are more dominant after model tuning. 